\title{
Article \\ Performance Analysis on the Use of Oscillating Water Column in Barge-Based Floating Offshore Wind Turbines
}

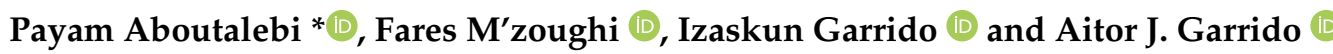 \\ Automatic Control Group-ACG, Institute of Research and Development of Processes-IIDP, \\ Department of Automatic Control and Systems Engineering, Faculty of Engineering of Bilbao, University of the \\ Basque Country_UPV/EHU, Po Rafael Moreno no3, 48013 Bilbao, Spain; fares.mzoughi@ehu.eus (F.M.); \\ izaskun.garrido@ehu.eus (I.G.); aitor.garrido@ehu.eus (A.J.G.) \\ * Correspondence: payam.aboutalebi@ehu.eus; Tel.: +34-94-601-4469
}

Citation: Aboutalebi, P.; M'zoughi,

F.; Garrido I.; Garrido A.J.

Performance Analysis on the Use of Oscillating Water Column in BargeBased Floating Offshore Wind

Turbines. Mathematics 2021, 9, 475.

https://doi.org/10.3390/math9050475

Academic Editor: Marek Lampart

Received: 25 January 2021

Accepted: 22 February 2021

Published: 25 February 2021

Publisher's Note: MDPI stays neutral with regard to jurisdictional claims in published maps and institutional affiliations.

Copyright: (c) 2021 by the authors. Licensee MDPI, Basel, Switzerland. This article is an open access article distributed under the terms and conditions of the Creative Commons Attribution (CC BY) license (https:// creativecommons.org/licenses/by/ $4.0 /)$.

\begin{abstract}
Undesired motions in Floating Offshore Wind Turbines (FOWT) lead to reduction of system efficiency, the system's lifespan, wind and wave energy mitigation and increment of stress on the system and maintenance costs. In this article, a new barge platform structure for a FOWT has been proposed with the objective of reducing these undesired platform motions. The newly proposed barge structure aims to reduce the tower displacements and platform's oscillations, particularly in rotational movements. This is achieved by installing Oscillating Water Columns (OWC) within the barge to oppose the oscillatory motion of the waves. Response Amplitude Operator (RAO) is used to predict the motions of the system exposed to different wave frequencies. From the RAOs analysis, the system's performance has been evaluated for representative regular wave periods. Simulations using numerical tools show the positive impact of the added OWCs on the system's stability. The results prove that the proposed platform presents better performance by decreasing the oscillations for the given range of wave frequencies, compared to the traditional barge platform.
\end{abstract}

Keywords: floating offshore wind turbine; oscillating water column; wave energy; wind energy; stabilization; response amplitude operator

\section{Introduction}

The growing trend of energy consumption in the world, scarcity of land for installation of onshore wind turbines and drawbacks of fossil fuels usage are the incentives for improvement of energy harvesting projects based on clean and renewable energies in oceans [1,2]. Offshore wind and wave resources are considered to be two forms of clean and renewable energies with vast area for deployment [3,4]. FOWTs have become an emerging trend in wind energy exploration in the past few years [5-7]. They offer the possibility of cheap and clean power supply for highly populated countries with access to a deep offshore area, such as coastal cities in the US, Spain, Japan, Korea, Norway, and Morocco [8,9]. Also, FOWTs are being built to have a capability of adding wave energy converters [10]. One of the most investigated class is the OWC [11,12].

The combination of a FOWT and an OWC has a great potential to harness both renewable energies from wind and wave resources. Potential energies of $350 \mathrm{GW}$ from wind and $320 \mathrm{GW}$ from waves can be harvested in the European coasts, which is equivalent to $50 \%$ from Wind, $46 \%$ from waves and $4 \%$ from tidal [13]. A hybrid FOWT-OWCs system can reduce the system's balancing costs [14], smooth power output [15], decrease the cost of offshore wind power energy [16] and increase the efficiency of the system. Moreover, common grid infrastructure, shared logistics, shared operation and maintenance are taken into account as some advantages of the combined system [13].

However, FOWTs need to be stabilized since platform motion is undesirable. It makes the rotor aerodynamics and control more complex and reduces aerodynamic efficiency [17]. Additionally, platform motion increments stresses on the blades, rotor shaft, yaw bearing, 
and tower base [18] and it can reduce the tower lifespan. FOWT's platform motions in pitch, roll and heave must be limited within acceptable range [19]. Some researchers hypothesized that the platform stabilization may decrease the platform steel mass, active ballast or/and taut mooring lines [20].

To harness the maximum energy from FOWTs, platform stabilization and vibration reduction are required [21]. Several previous articles proposed different approaches to reduce the oscillations in FOWTs. In Reference [22], Z. Zhang et al. proposed a generator model to provide a feedback control torque to suppress the lateral tower vibrations in offshore wind turbines. W. Yang et al. [23] used motion stabilizers as heave plates connected to the foundation of the spar-type FOWT for the stabilization. Several articles investigated the application of inerters to a barge-type FOWT to mitigate loads of the FOWTs exposed by winds and waves [24]. Y. Zhang et al. in [25] discussed a nonlinear dynamic model of a FOWT equipped with Tuned Mass Damper (TMD) and controlled by sliding mode algorithm. X. Wei et al. in [26] mitigated the barge pitch and roll motions of floating hydrostatic wind turbine by combining the advantages of the bidirectional tuned liquid column damper and the tuned mass damper.

There are many articles using combined FOWT and Wave Energy Converters (WEC) to create a multi-purpose platform that absorbs both wind and wave energies [27-31]. However, there are a few articles proposing OWCs included in FOWTs with stabilization as the main objective. In References [19,20], J.M. Kluger et al. combined a spar platform known as OC3-Hywind FOWT with WEC array to reduce its oscillations. A. Slocum et al. in [32] compared an external and internal heave WEC on OC3-Hywind FOWT. M. Kamarlouei et al. in [33], concluded that installation of a WEC array can reduce the FOWT platform motions in heave and pitch. However, the introduced approaches have not used OWCs in barge-based FOWT platforms.

Although OWCs have been applied in different FOWTs especially spar-type ones to decrease the motions, the application of OWCs in barge-based FOWTs for stabilization has not yet been reported. This work aims to study the nonlinear model of NREL 5-MW baseline ITI Energy barge wind turbine. The FOWT model is fully coupled aero-hydro-servo-elastic described in frequency domain [34]. A novel platform design has been proposed in this work to reduce the undesired oscillating motions of the floating platform, particularly in rotational modes. The standard barge platform design has been redesigned to house four OWCs to reduce the oscillations in the barge platform. Performance analysis of the system has been evaluated in frequency and time domains. To achieve this goal, RAOs for platforms' modes have been analyzed to understand the behaviour of the system in frequency domain and then four periods from the obtained RAOs have been chosen to analyze the system in time domain. A comparison between both standard barge platform and the proposed platform with four OWCs has been provided to evaluate the platforms' performance.

The structure of this article is organized as follows. Section 2 introduces some theoretical background on the waves, the FOWT model with the OWC. In Section 3, the methodology of the work to perform the advanced computations of the coupled aerohydro-servo-elastic properties using MultiSurf, WAMIT and FAST tools is explained. In Section 4, a frequency domain analysis has been performed to select wave periods to setup time domain study cases. Four study cases have been carried out to analyze the performance of the system in all sea states. Section 5 finishes the article with some concluding remarks and future control perspectives.

\section{Theoretical Background}

In this research work, unidirectional regular waves are considered to be the input. To express its surface dynamics the Airy wave theory can be used to describe it as $[35,36]$ :

$$
z(t)=A \sin (\omega t)=A \sin (2 \pi f t)=A \sin \left(\frac{2 \pi}{\lambda} c t\right)
$$


where $c=\lambda f$ is the propagation speed. $A$ is the wave amplitude from Still Water Level $(S W L)$ to the wave crest, and $\lambda$ is the wavelength, which is the distance between successive crests. Equation (1) describes the temporal variation of a wave as a macroscopic representation of the oscillating motion of water particles at a specific point. To transfer the oscillating behavior to any point on the surface of the wave, a new variable representing the spatial dimension in the wave's front direction is introduced. Therefore, Equation (1) becomes:

$$
z(x, t)=A \sin \left(\frac{2 \pi}{\lambda}(c t-x)\right)
$$

and by introducing the wave number $k=2 \pi / \lambda$, Equation (2) becomes:

$$
z(x, t)=A \sin (\omega t-k x)=\frac{H}{2} \sin (\omega t-k x)
$$

where $H$ is wave height from the wave trough to the wave crest.

In this research, the motion equations of a 5-MW FOWT have been used which is installed on a barge platform that houses one OWC in each of its four corners. The complete nonlinear time-domain equations of motion of the coupled floating wind turbine, support platform system and OWCs are of the general form as:

$$
M_{i j}(q, u, t) \ddot{q}_{j}=f_{i}(q, \dot{q}, u, t)
$$

where $M_{i j}$ is the $(i, j)$ component of the inertia mass matrix, $u$ is the control inputs, $t$ is time, $\ddot{q}_{j}$ is the second time derivative of the $j$ th Degree Of Freedom (DOF) and $f_{i}$ is the component of the forcing function associated with $i$ th DOF .

The term on the right-hand side of Equation (4) is the generalized outside force applying to the system, including the aerodynamic load on the blades and the nacelle, hydrodynamic force on the platform, elastic and servo forces. This study does not consider wind and servo forces for yaw, pitch and generator control of the wind turbine. Hence, the total number of DOFs evaluated is eight consisting of surge, sway, heave, roll, pitch, yaw, fore-aft and side-to-side displacements, as shown in Figure 1. The origin of the coordinate system is at still water line.

The system linear equations of motion in frequency domain is written as:

$$
I_{F O W T}(\omega) \ddot{q}+B_{F O W T}(\omega) \dot{q}+C_{F O W T} q=\vec{f}_{F O W T}(\omega)+\vec{f}_{P T O}(\omega)
$$

where $I_{F O W T}, B_{F O W T}$ and $C_{F O W T}$ are inertia, damping and stiffness matrices, respectively. $\vec{f}_{F O W T}(\omega)$ and $\vec{f}_{\text {PTO }}(\omega)$ represent the hydrodynamic force and viscous drag of the waves on the platform and the load induced by the Power-Take-Off (PTO) equipment respectively. $q$ from Equation (5) is defined as:

$$
q=\left[\begin{array}{c}
\text { surge } \\
\text { sway } \\
\text { heave } \\
\text { roll } \\
\text { pitch } \\
\text { yaw } \\
\text { fore-aft } \\
\text { side-to-side }
\end{array}\right]
$$

The inertia matrix of the FOWT system is defined by Equation (7) as:

$$
I_{\text {FOWT }}(\omega)=A_{\text {Hydro }}(\omega)+M_{\text {Platform }}+M_{\text {Tower }}
$$

where $M_{\text {Platform }}$ and $M_{\text {Tower }}$ are platform and tower mass matrices, respectively. Platform mass matrix is expressed as: 


$$
M_{\text {Platform }}=\left[\begin{array}{cccccc}
m_{1} & 0 & 0 & 0 & L_{Z} m_{1} & -L_{Y} m_{1} \\
0 & m_{2} & 0 & -L_{Z} m_{2} & 0 & L_{X} m_{2} \\
0 & 0 & m_{3} & L_{Y} m_{3} & -L_{X} m_{3} & 0 \\
0 & -L_{Z} m_{2} & L_{Y} m_{3} & \beta_{1} & L_{X} L_{Y} m_{3} & -L_{X} L_{Z} m_{2} \\
L_{Z} m_{1} & 0 & -L_{X} m_{3} & L_{X} L_{Y} m_{3} & \beta_{2} & -L_{Y} L_{Z} m_{1} \\
-L_{Y} m_{1} & L_{X} m_{2} & 0 & -L_{X} L_{Z} m_{2} & -L_{Y} L_{Z} m_{1} & \beta_{3}
\end{array}\right]
$$

and the diagonal terms are defined as follows:

$$
\begin{aligned}
& \beta_{1}=I_{44}+L_{Z}^{2} m_{2}+L_{Y}^{2} m_{3} \\
& \beta_{2}=I_{55}+L_{X}^{2} m_{3}+L_{Z}^{2} m_{1} \\
& \beta_{3}=I_{66}+L_{Y}^{2} m_{1}+L_{X}^{2} m_{2}
\end{aligned}
$$

where $m_{1}, m_{2}$ and $m_{3}$ are inertial mass in three translational directions, which are equal. $I_{44}, I_{55}$ and $I_{66}$ are the inertial mass in three rotational directions. $L_{X}, L_{Y}$ and $L_{Z}$ are the position of the structure's center of mass in the still water level coordinates. The mass matrix of the tower is $8 \times 8$ matrix containing elements coupling the tower bending with the tower rigid heave motion. $A_{\text {Hydro }}$ is the platform's added mass calculated by WAMIT from the panel radiation program and it is frequency-dependent.

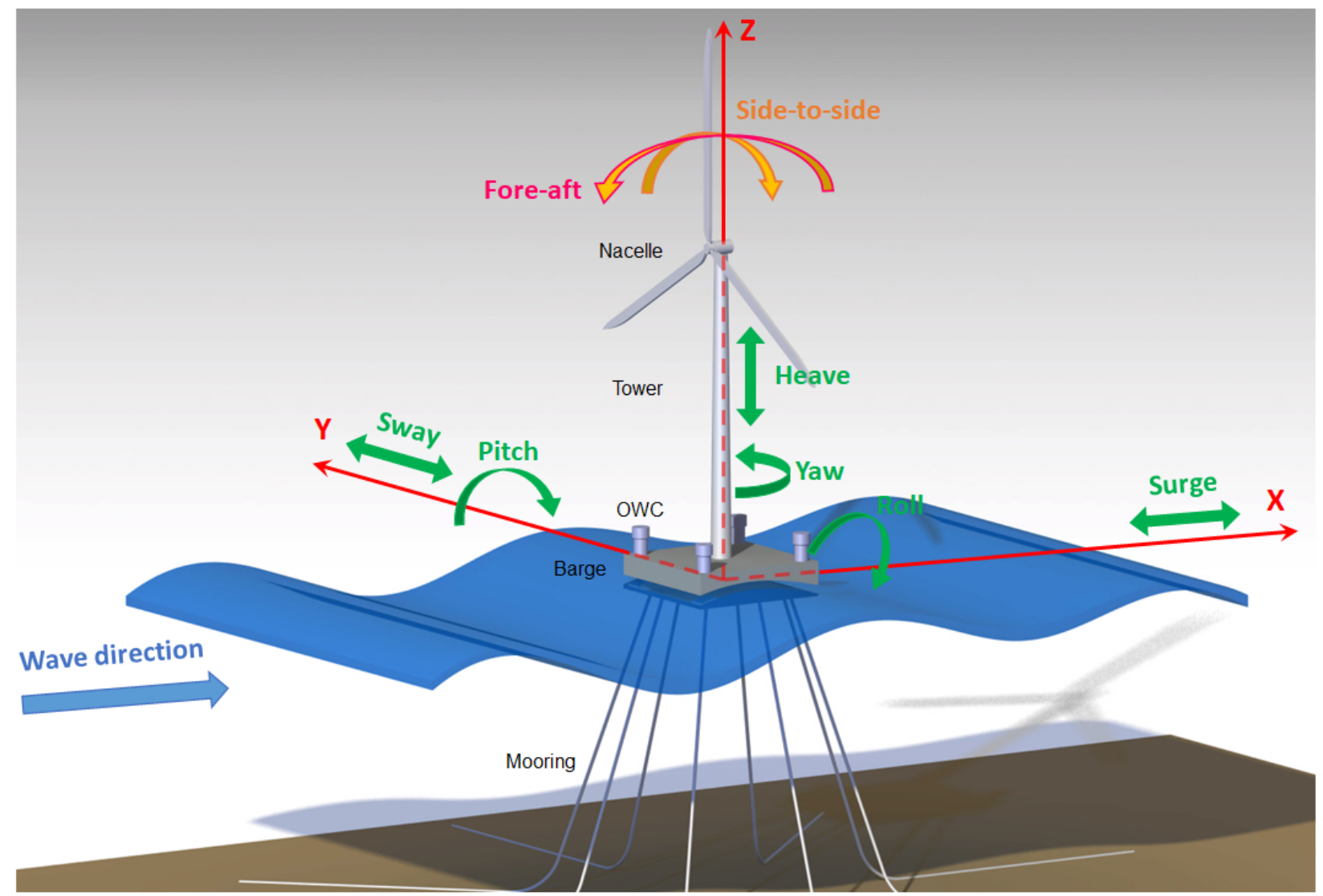

Figure 1. Barge-based floating offshore wind turbine with four OWCs.

Equation (6) shows the modes of the system with the six first ones for the platform motions and the two last ones for the tower bending displacements.

The stiffness matrix $C_{F O W T}$ is defined as:

$$
C_{\text {FOWT }}=C_{\text {Hydro }}+C_{\text {Mooring }}+C_{\text {Tower }}
$$


where $C_{\text {Hydro }}$ is the platform' hydrostatic restoring matrix obtained by WAMIT and $C_{\text {Mooring }}$ contains the mooring lines spring stiffness coefficients and $C_{\text {Tower }}$ is the tower stiffness matrix.

The damping matrix is given by:

$$
B_{F O W T}(\omega)=B_{\text {Hydro }}(\omega)+B_{\text {Tower }}+B_{\text {viscous }}+B_{\text {chamber }}
$$

where $B_{H y d r o}$ is the floating platform's damping matrix. $B_{\text {Tower }}$ and $B_{\text {viscous }}$ are damping matrix of the flexible tower and the nonlinear viscous drag on the platform, respectively. $B_{\text {chamber }}$ is the effect of the PTO on the overall dynamics represented as the external force. Assuming that the internal free surface behaves like a piston, the pressure is uniform inside the chamber [28]. Therefore, the external force is defined as:

$$
f_{\text {PTO }}(\omega)=-p(\omega) S
$$

where $p$ is the pressure drop across the turbine and $S$ is the internal free surface area. Considering the air as an ideal gas and the air compression and decompression as an isentropic process, the time-dependent air density can be given by:

$$
\rho=\rho_{a}\left(\frac{p}{p_{a}}\right)^{\frac{1}{\gamma}}
$$

where $\rho_{a}$ and $p_{a}$ are the density and pressure representing the state of the chamber at rest and $\gamma$ describes the heat capacity ratio of air. After linearization of the time derivative of Equation (15), the following equation is obtained:

$$
\dot{\rho}=\frac{\rho_{a}}{\gamma p_{a}} \dot{p}
$$

The linearized mass flow inside the turbine can be given by [37]:

$$
\dot{m}=\frac{d(\rho V)}{d t}=\frac{\rho_{a}}{\gamma p_{a}} \dot{p} V_{a}+\rho_{a} \dot{V}
$$

where $V$ is the air volume through the chamber and $V_{a}$ is the air volume in the chamber in an undisturbed condition.

Using non-dimensional turbo-machinery nomenclature, a Wells turbine of diameter $D$ and rotational velocity $N$ is characterized by a linear relation between the pressure and flow coefficients:

$$
\Psi=\mathrm{K} \Phi
$$

where the pressure and flow coefficients are described as:

$$
\begin{aligned}
\Psi & =\frac{p}{\rho_{a} N^{2} D^{2}} \\
\Phi & =\frac{\dot{m}}{\rho_{a} N D^{3}}
\end{aligned}
$$

The pressure drop is considered proportional to the flow rate. Hence, nondimensionalization is used and the linear relation is defined by:

$$
\Psi_{c}=\mathrm{K}_{c} \Phi_{c}
$$

where the pressure and flow coefficients are expressed as:

$$
\Psi_{c}=\frac{p}{\rho_{a} g H}
$$




$$
\Phi_{c}=\frac{2 \pi \dot{m}}{\rho_{a} \omega S H}
$$

where $g$ is gravitational acceleration value. Therefore, introducing Equations (21)-(23) into Equation (17), the mass flow inside the turbine is described as:

$$
\dot{m}(\omega)=\frac{S \omega}{2 \pi g K_{c}}
$$

By combining Equations (17) and (24), the pressure complex amplitude can be expressed as:

$$
\hat{p}(\omega)=i \omega \frac{\Gamma}{S \omega\left[1+(\varepsilon \Gamma)^{2}\right]} \hat{V}-\omega^{2} \frac{\varepsilon \Gamma^{2}}{S \omega\left[1+(\varepsilon \Gamma)^{2}\right]} \hat{V}
$$

where $\hat{V}$ is the complex amplitude of the air volume oscillation and the constants $\Gamma$ and $\varepsilon$ are given by:

$$
\begin{aligned}
\Gamma & =2 \pi \rho_{a} g K_{c} \\
\varepsilon & =\frac{V_{a}}{\gamma p_{a} S}
\end{aligned}
$$

According to Equations (14) and (25), the PTO force is described as:

$$
\hat{f}_{\text {PTO }}(\omega)=-i \omega B_{\text {PTO }} \hat{q}_{r}+\omega^{2} K_{\text {PTO }} \hat{q}_{r}
$$

where $\hat{q}_{r}$ is the complex amplitude of the relative displacement. According to the aforementioned Equation (25), the PTO damping and stiffness coefficients are as follows:

$$
B_{\text {РTO }}(\omega)=\frac{\Gamma S}{\omega\left[1+(\varepsilon \Gamma)^{2}\right]}
$$

and

$$
K_{\text {PTO }}(\omega)=\frac{\varepsilon \Gamma^{2} S}{\omega^{2}\left[1+(\varepsilon \Gamma)^{2}\right]}
$$

Finally, the system of motion equations for the 8-DOF of the FOWT, given by Equation (5), in the frequency domain, may be rewritten as:

$$
I_{F O W T}(\omega) \ddot{q}+\left(B_{F O W T}(\omega)+B_{P T O}(\omega)\right) \dot{\hat{q}}+\left(C_{F O W T}+K_{P T O}(\omega)\right) \hat{q}=\vec{f}_{F O W T}(\omega)
$$

The term on the right-hand side of Equation (31) is described as:

$$
\vec{f}_{\text {FOWT }}(\omega)=\vec{f}_{\text {Hydro }}(\omega)+\vec{f}_{\text {viscous }}(\omega)
$$

where $\vec{f}_{\text {viscous }}$ is the viscous force and $\vec{f}_{\text {Hydro }}$ is the hydrodynamic force of the waves on the platform. $\vec{f}_{\text {Hydro }}$ can be obtained from the panel diffraction program of WAMIT.

\section{Methodology}

This section presents and explains the materials and methods used to achieve this research work. The structure of this section is organized as follows. Section 3.1 introduces the modeling and design of the newly proposed 4OWC-based barge platform structure. In Section 3.2, advanced computations were carried out with the designed platform to calculate the structure's added mass, damping matrix, hydrostatic matrix and hydrodynamic forces. Section 3.3 incorporates the obtained parameters into the aforementioned model equations to perform numerous simulations. In Section 3.4, the system is analyzed using $\mathrm{RAO}$ indicators to evaluate the behaviour of the system in various frequencies. 


\subsection{OWC-Based Platform Design}

MultiSurf is used to design the geometry of the platforms. Two different platforms with varied features have been compared. The first platform is a standard barge platform which can be seen in Figure 2 while the second one belongs to a barge platform with consideration of four OWCs at the corners showed in Figure 3.

Consistent with linear theory, only the wetted portion of the body is meshed in its undisplaced position [34] via MultiSurf. In this study, the calculated draft is $4 \mathrm{~m}$. The standard barge platform is modeled with 2240 rectangular panels within a quarter of the body. The barge with two geometric planes of symmetry with respect to $x$-axis and $y$-axis is modeled.

The second platform with 9840 total rectangular panels is modeled and the OWCs have a distance of one meter from the sides of the platform with the dimensions $5 \mathrm{~m} \times 5 \mathrm{~m} \times 10 \mathrm{~m}$.

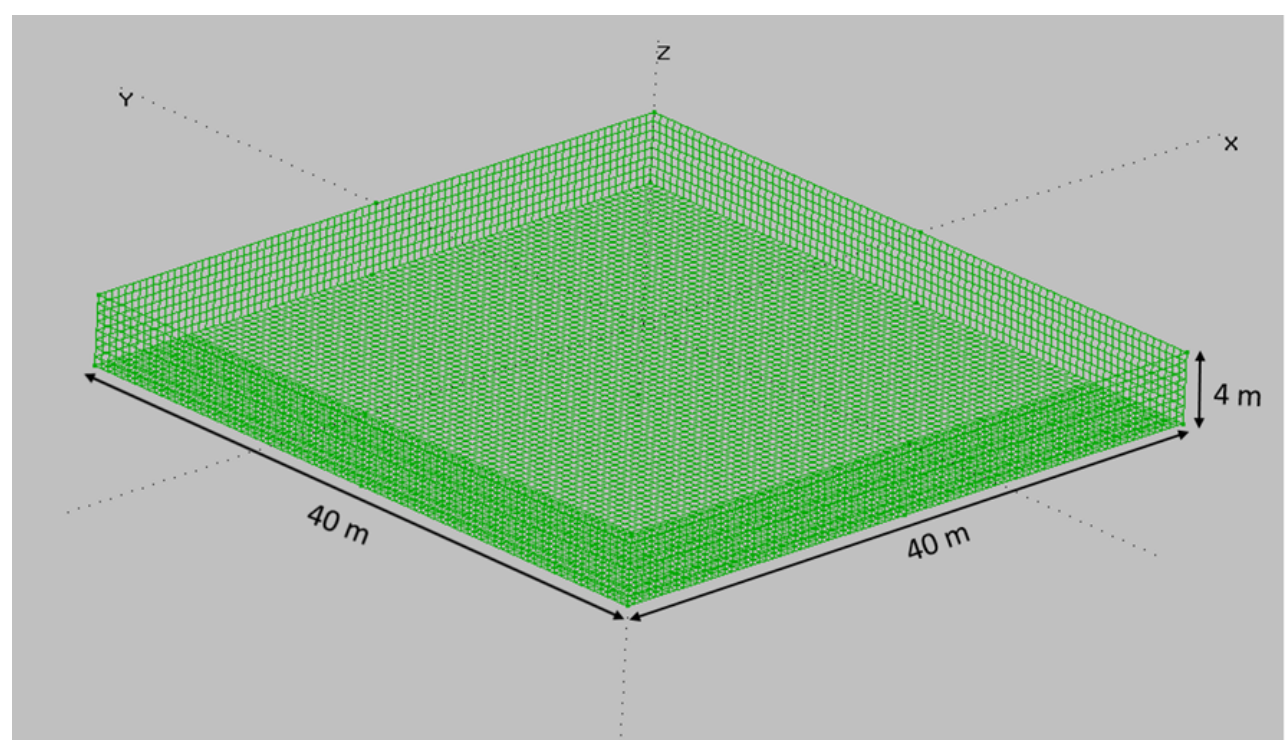

Figure 2. Geometry of the standard barge platform.

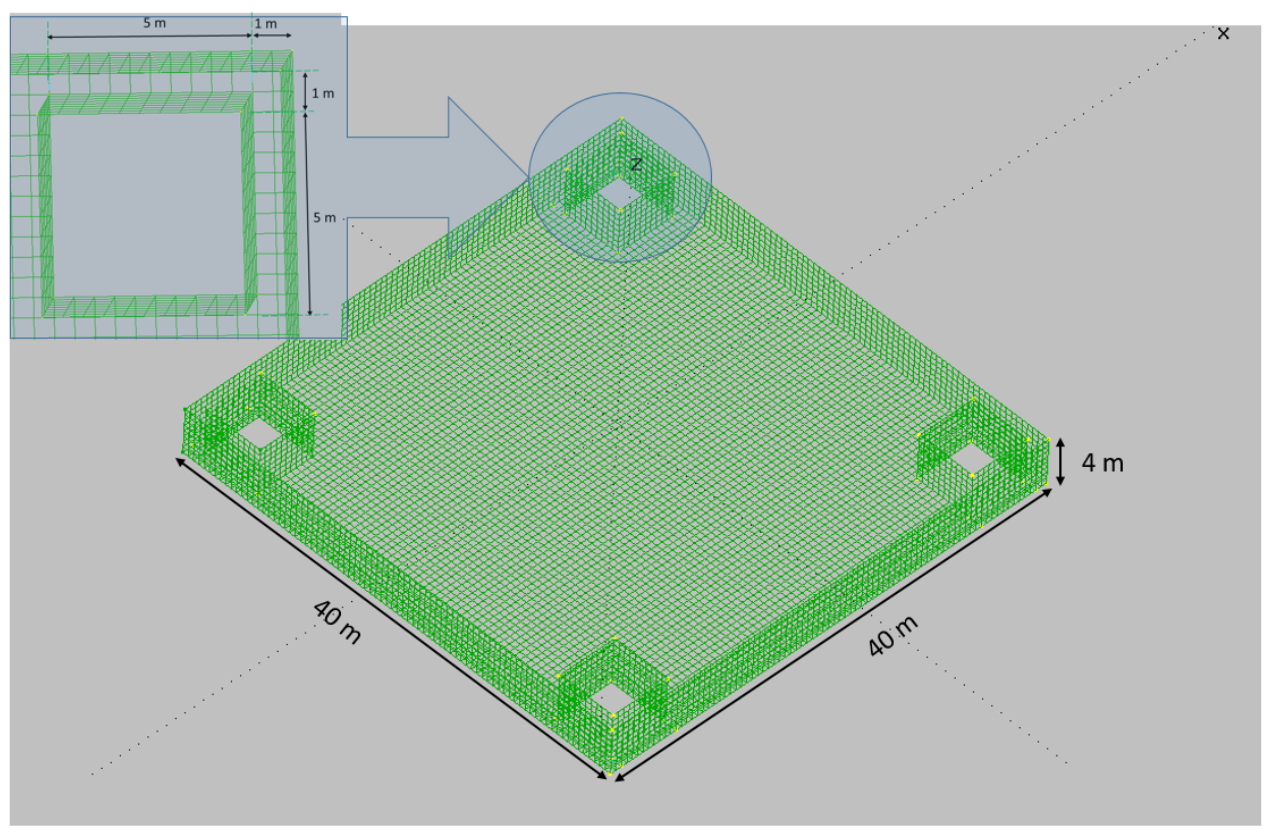

Figure 3. Geometry of the platform with four OWCs.

Table 1 details the characteristics of the barge platform and the 4OWC platform. 
Table 1. Characteristics of the standard barge platform and the 4OWC-based barge platform.

\begin{tabular}{cc}
\hline Parameter & Value \\
\hline Size $(\mathrm{W} \times \mathrm{L} \times \mathrm{H})$ for both platforms & $40 \mathrm{~m} \times 40 \mathrm{~m} \times 10 \mathrm{~m}$ \\
Size $(\mathrm{W} \times \mathrm{L} \times \mathrm{H})$ for each OWC & $5 \mathrm{~m} \times 5 \mathrm{~m} \times 10 \mathrm{~m}$ \\
Draft, Free board for both platforms & $4 \mathrm{~m}, 6 \mathrm{~m}$ \\
Water displacement for the simple barge & $6400 \mathrm{~m}^{3}$ \\
Water displacement for the barge with OWCs & $6000 \mathrm{~m}^{3}$ \\
Mass, Including Ballast & $5,452,000 \mathrm{~kg}$ \\
CM Location below SWL & $0.281768 \mathrm{~m}$ \\
Roll Inertia about CM & $726,900,000 \mathrm{~kg} \cdot \mathrm{m}^{2}$ \\
Pitch Inertia about CM & $726,900,000 \mathrm{~kg} \cdot \mathrm{m}^{2}$ \\
Yaw Inertia about CM & $1,453,900,000 \mathrm{~kg} \cdot \mathrm{m}^{2}$ \\
Anchor (Water) Depth & $150 \mathrm{~m}$ \\
Unstretched Line Length & $773.8 \mathrm{~m}$ \\
Separation between Opposing Anchors & $473.3 \mathrm{~m}$ \\
Line Diameter & $250 \mathrm{~m}$ \\
Line Mass Density & $0.0809 \mathrm{~m}$ \\
Line Extensional Stiffness & $130.4 \mathrm{~kg} / \mathrm{m}$ \\
\hline
\end{tabular}

\subsection{Advanced Hydrostatic and Hydrodynamic Computations}

Panel method WAMIT was used to get the matrices $A_{H y d r o}(\omega), B_{H y d r o}(\omega), C_{H y d r o}$ and $f_{\text {Hydro }}(\omega)$ described in Section 2. This advanced computational tool provides analysis of interaction between wave inputs and floating offshore platforms. WAMIT calculates the hydrodynamics loads resulted from water pressure on the wetted surfaces and can be linked to MultiSurf to use the geometric floating model.

The relationship between the added mass and damping coefficients is defined by:

$$
A_{i j}-\frac{i}{\omega} B_{i j}=\rho \iint_{S b} n_{i} \varphi_{j} d S
$$

Thus, the normalized added mass and damping coefficients are:

$$
\begin{aligned}
\bar{A}_{i j} & =A_{i j} / \rho L^{k} \\
\bar{B}_{i j} & =B_{i j} / \rho L^{k} \omega
\end{aligned}
$$

where $L$ is the length scale, $k=3$ for $(i, j=1,2,3), k=4$ for $(i=1,2,3),(j=4,5,6)$ or $(i=4,5,6),(j=1,2,3)$ and $k=5$ for $(i, j=4,5,6)$.

All hydrostatic data can be expressed in the form of surface integrals over the mean body wetted surface $S_{b}$, by virtue of Gauss' divergence theorem. Volume is defined as:

$$
\forall=-\iint_{S_{b}} n_{1} x d S=-\iint_{S_{b}} n_{2} y d S=-\iint_{S_{b}} n_{3} z d S
$$

Coordinates of center of buoyancy are given by:

$$
\begin{aligned}
& x_{b}=\frac{-1}{2 \forall} \iint_{S_{b}} n_{1} x^{2} d S \\
& y_{b}=\frac{-1}{2 \forall} \iint_{S_{b}} n_{2} y^{2} d S \\
& z_{b}=\frac{-1}{2 \forall} \iint_{S_{b}} n_{3} z^{2} d S
\end{aligned}
$$

Matrix of hydrostatic and gravitational restoring coefficients are defined as: 


$$
C_{H y d r o}=\left[\begin{array}{cccccc}
0 & 0 & 0 & 0 & 0 & 0 \\
0 & 0 & 0 & 0 & 0 & 0 \\
0 & 0 & \rho g \iint_{S_{b}} n_{3} d S & \rho g \iint_{S_{b}} y n_{3} d S & -\rho g \iint_{S_{b}} x n_{3} d S & 0 \\
0 & 0 & 0 & \rho g \iint_{S_{b}} y^{2} n_{3} d S+\zeta & -\rho g \iiint_{S_{b}} x y n_{3} d S & \rho g \forall x_{b}+m g x_{g} \\
0 & 0 & 0 & 0 & \rho g \iint_{S_{b}} x^{2} n_{3} d S+\zeta & -\rho g \forall y_{b}+m g y_{g} \\
0 & 0 & 0 & 0 & 0 & 0
\end{array}\right]
$$

where $\left(x_{g}, y_{g}, z_{g}\right)$ are the coordinates of the center of gravity and $\zeta=\rho g \forall z_{b}-m g z_{g}$.

\subsection{Proposed Platform and Tower Integration}

FAST (Fatigue, Aerodynamics, Structures, and Turbulence) joins aerodynamics, hydrodynamics models for offshore structures, control and electrical system (servo) dynamics models, and structural (elastic) dynamics models to enable coupled nonlinear aero-hydroservo-elastic simulation in the time domain. The FAST tool enables the analysis of a range of wind turbine configurations, including two- or three-blade horizontal-axis rotor, pitch or stall regulation, rigid or teetering hub, upwind or downwind rotor, and lattice or tubular tower.

The offshore dynamic responses has been incorporated within FAST implementing nonlinear equations of motion for 5-MW offshore wind turbine. The properties of the offshore turbine are provided in Table 2.

Table 2. Properties of 5-MW floating wind turbine [38].

\begin{tabular}{cc}
\hline Parameter & Value \\
\hline Hub height & $90 \mathrm{~m}$ \\
Center of mass location & $38.23 \mathrm{~m}$ \\
Rotor diameter & $126 \mathrm{~m}$ \\
Number of blades & 3 \\
Initial rotational speed & $12.1 \mathrm{rpm}$ \\
Blades mass & $53.22 \mathrm{~kg}$ \\
Nacelle mass & $240,000 \mathrm{~kg}$ \\
Hub mass & $56,780 \mathrm{~kg}$ \\
Tower mass & $347,460 \mathrm{~kg}$ \\
Power output & $5 \mathrm{MW}$ \\
Cut-in, Rated, Cut-out wind speed & $3 \mathrm{~m} / \mathrm{s}, 11.4 \mathrm{~m} / \mathrm{s}, 25 \mathrm{~m} / \mathrm{s}$ \\
\hline
\end{tabular}

\subsection{OWC-Based Platform's Motions Evaluation}

To evaluate the response motions of a floating object, obtaining a generic procedure to have an input-output system is significant. A floating platform response can be predicted from wave inputs with different frequencies. To achieve that goal, analysis of Response Amplitude Operators (RAO) plays an important role. In design of FOWTs, the hydrodynamic loads, aerodynamics, structural dynamics (including blade and tower flexibility), and controller dynamics should be taken into account because they have an important effect on the whole system and its motion responses [39].

The nonlinear dynamics of the FOWT excited by hydrodynamic and aerodynamic loads requires a highly advanced tool which makes the RAOs computation accurate, hence FAST v8 has been used. Such a system is excited by white-noise wave input in time-domain for obtaining RAOs.

A specific procedure has been followed to plot the RAOs for the rotational and transnational motions as system's outputs. First, using the geometric data from MultiSurf, WAMIT calculations are performed for introducing added-mass, damping matrices, hydrostatics coefficients and hydrodynamic loads to be taken into account for the equations of motion. Then the equations are employed in FAST to achieve system's outputs. Calculation of RAOs for every system's mode via the auto-spectral density of the input (wave elevation) 
and the cross-spectral density of the input/output (system responses) is conducted. Aforementioned procedure should be performed for $M$ times with different seeds for production of white noises as system's wave input. Next the first seconds from each computation is removed for transient effects. Finally, the average sets are calculated. The reason of calculating the average sets is that averaging over different realizations smooths the spectrum. The peaks and drops disappear and the histogram become concentrated around its mean value [40]. Also, it reduces the leakage effects with a lower noise sensitivity.

The RAO calculated in the procedure is defined as:

$$
R A O=\frac{S_{x y}(\omega)}{S_{x x}(\omega)}
$$

where $S_{x y}(\omega)$ and $S_{x x}(\omega)$ are the cross-spectral and auto-spectral densities of the input $x(t)$ and the output $y(t)$, in the frequency domain, respectively. $S_{x y}(\omega)$ and $S_{x x}(\omega)$ can be defined as follows:

$$
\begin{aligned}
& S_{x y}(\omega)=\frac{1}{M} \sum_{s=1}^{M} Y^{[s]}(r) \bar{X}^{[s]}(r) \\
& S_{x x}(\omega)=\frac{1}{M} \sum_{s=1}^{M} X^{[s]}(r) \bar{X}^{[s]}(r)
\end{aligned}
$$

with $X^{[s]}$ the Fast Fourier Transform (FFT) spectrum of segment $s . M$ is the number of simulations of the procedure and $r$ is the random noise sequence. $\bar{X}$ is the complex conjugate of $X$.

Random noise excitations are used for obtaining RAOs because their use is very popular in practical applications and also it seems much accurate to generate and use random noise excitations than periodic signals.

The Results of using the above procedure in order to plot the RAOs are shown in the following Section 4. Besides, different frequencies are chosen to demonstrate the performance of the platforms in various sea states.

\section{Results and Discussion}

The wind turbine selected in this article is 5-MW floating wind turbine, which can be found in [38]. This floating wind turbine is installed on a barge platform. J. Jonkman et al. proposed a simple barge with a moonpool covered by a lid [34] and this moonpool can be used for installation of an OWC.

Our proposed model is a platform with four OWCs located symmetrically at each corner that is compared with a standard barge platform without any OWCs.

To have maximum energy production by FOWTs, we need to minimize the oscillations in the platform created by waves [21]. In this section, figures show how the new model can have significant impact on the reduction of oscillations in translational and rotational modes under specific sea states. In this work, rotational modes including roll, pitch and yaw are more important since finally decrease the vibrations on two modes of the FOWT consisting of fore-aft and side-to-side displacements is needed.

In this section, first the RAOs' results are indicated in different sea states and then platforms displacements at specific frequencies based on RAO's curves are plotted.

\subsection{Response Amplitude Operators}

To assess the platforms' motions, RAOs can be analyzed and evaluated. In fact, RAOs for system's modes give the ability to decide which platform has the better performance under varying sea states.

In the present study, the procedure in Section 3.4 and following numerical conditions for plotting RAOs are considered. Simulation time for every computation is $8000 \mathrm{~s}$ and $2000 \mathrm{~s}$ were removed from each computation for transient effects. Wave inputs have a 
height of $2 \mathrm{~m}$ with random white-noise to ensure the linear wave theory. Six computations are conducted for averaging $(M=6)$.

Additionally, some environmental conditions are assumed. First of all, heading waves of zero degree and still air condition is considered. Nonlinearities caused by the flexible tower, hydrodynamic loads, viscous effect and mooring lines are taken into account. Also, no servo control such as pitch, yaw and generator control is applied.

Figure 4 shows the wave input for one computation. For other computations, different seeds are considered but the wave heights are the same.

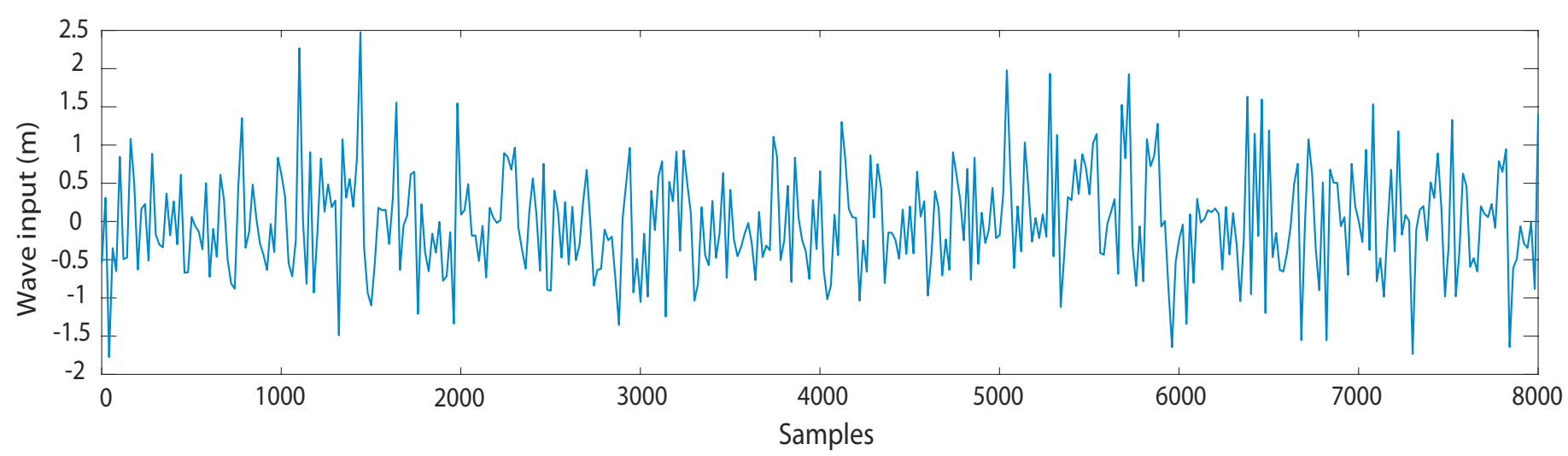

Figure 4. Wave input as white-noise.

In the present work, RAOs for six modes are plotted. Figure 5a-f show the RAOs for surge, sway, heave, roll, pitch and yaw. RAOs are plotted for the period range of 2-35 s $(0.0028-0.5 \mathrm{~Hz})$. Blue dash and red curves represent the RAOs for the standard barge platform and platform with four OWCs, respectively.

Because of the wave heading along surge direction and absence of the wind force, the excitations even at the resonance frequencies of sway, roll and yaw are considerably less than other states RAO, as shown in Figure $5 b, d$,f. Hence, small oscillations are expected for these modes.

There is a shift in period between the two platforms, shown in Figure 5a. From period $2 \mathrm{~s}$ to $7.5 \mathrm{~s}$ and $15 \mathrm{~s}$ to $35 \mathrm{~s}$, RAOs are almost the same and it is expected that both platforms move similarly in surge. Surge resonance frequencies occur at $0.084 \mathrm{~Hz}(11.9 \mathrm{~s})$ and $0.078 \mathrm{~Hz}$ (12.8 s) for the standard barge and 4OWC-based platforms, respectively.

Figure $5 \mathrm{c}$ shows the heave RAO (HRAO). It can be noticed that RAOs curves for both platforms are almost identical excluding from period $7.1 \mathrm{~s}$ to $10.3 \mathrm{~s}$ which HRAO for the standard barge platform is higher than that of the platform with four OWCs. Additionally, the curves indicate that the HRAOs follow the wave inputs for periods larger than $15 \mathrm{~s}$ which means that the heave output and wave input are similar.

Figure 5e indicates the most significant spectrum, in this study, that is pitch because of the importance of angle reduction in rotational modes rather than the transnational modes for getting the maximum energy from wind. The RAO for this mode is illustrated individually in Figure 6.

Through analyzing the Pitch RAO (PRAO), the platforms' performance under different sea states has been carried out. It is noticeable that both platforms start pitching from period $2 \mathrm{~s}$ and then the platforms' pitch increase to peak at their resonance periods at $11.9 \mathrm{~s}$ and $12.71 \mathrm{~s}$ for the standard barge platform and 4OWC-based barge platform, respectively. Then the platforms' pitch decrease for longer-period waves to reach to near zero. Figure 6 is divided into four regions, described as follows: 
(a)

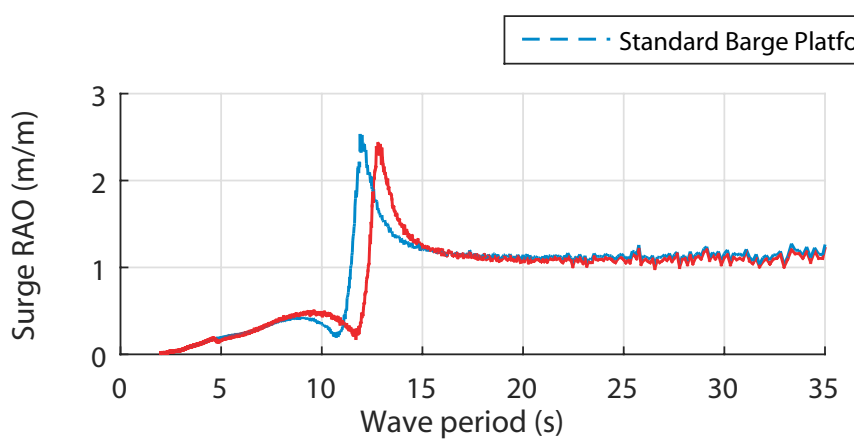

(b)

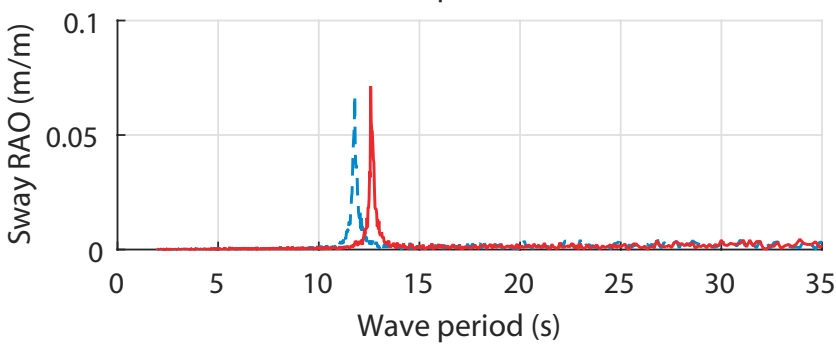

(c)

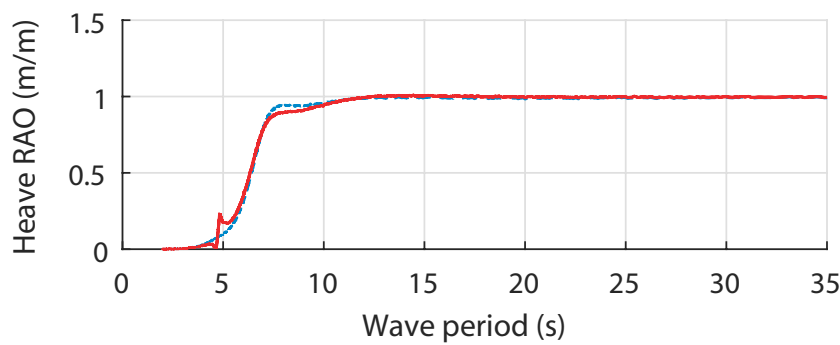

(d)

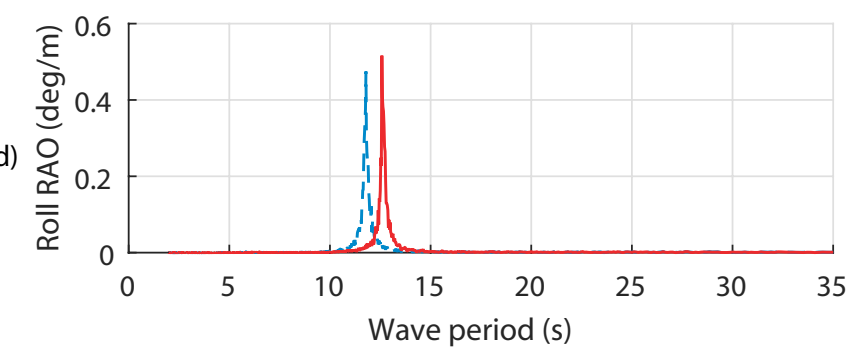

(e)

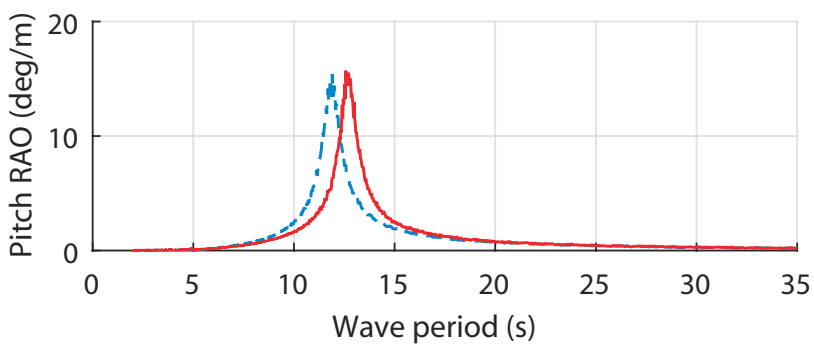

(f)

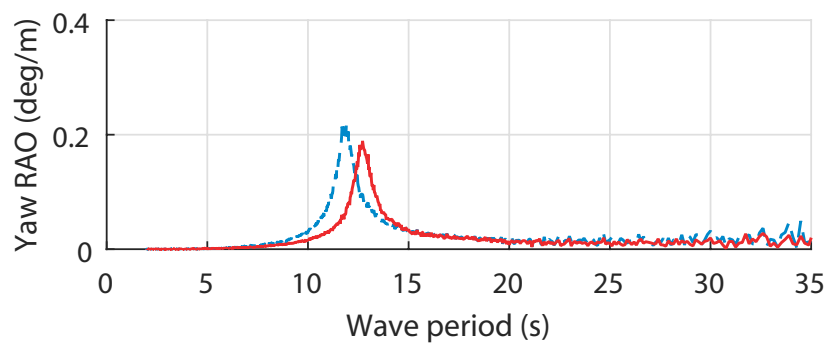

Figure 5. RAOs for (a) Surge, (b) Sway, (c) Heave, (d) Roll, (e) Pitch and (f) Yaw.

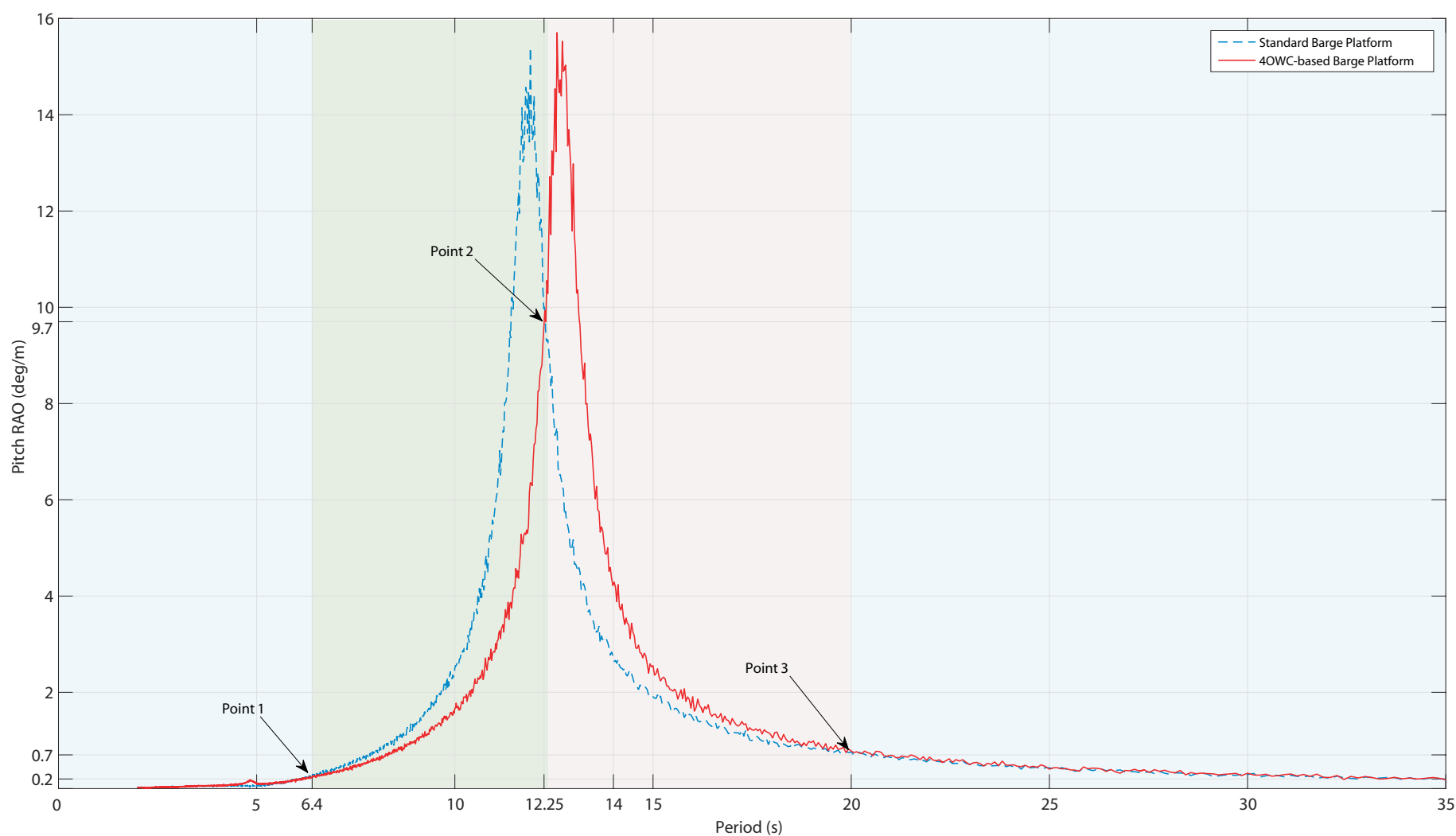

Figure 6. Standard barge platform and 4OWC-based barge platform pitch RAOs. 
The first region is from $2 \mathrm{~s}$ to $6.4 \mathrm{~s}$ (point 1) where both curves are almost identical. It is expected that the platforms' pitch have the same angle and minor oscillations in these periods. One period is chosen in this region for more detailed analysis after doing simulation in FAST (first chosen period $T=6 \mathrm{~s}$ ).

The second region highlighted in green is from $6.4 \mathrm{~s}$ (point 1) to $12.25 \mathrm{~s}$ (point 2). In this zone, PRAO for the proposed platform is lower than the standard barge. It means that the pitch oscillation for the proposed platform is less than that of the standard barge. The second chosen period in this zone is $10 \mathrm{~s}$.

The third region is from $12.25 \mathrm{~s}$ (point 2) to $20 \mathrm{~s}$ (point 3) highlighted in red. In this region, the reaction of the system to waves input is different and PRAO for our proposed platform is higher than a standard barge. Therefore, it is predictable to have less oscillation with the standard barge platform, compared to the proposed one. $T=14 \mathrm{~s}$ is considered in this zone for more analysis.

The last region from $20 \mathrm{~s}$ (point 3) to $35 \mathrm{~s}$ is like the first region because two curves are identical. The considered period is the period of $30 \mathrm{~s}$ in this zone.

Briefly, Simulation results for more detailed analysis are discussed in the next subsection for four periods ( $T=6 \mathrm{~s}, 10 \mathrm{~s}, 14 \mathrm{~s}$ and $30 \mathrm{~s}$ ).

\subsection{Performance Analysis in Different Sea Conditions}

By analyzing the RAOs for six modes of the system from last subsection, four periods have been chosen for obtaining more details of the system's behaviour in this subsection.

To investigate the performance of the proposed platform in comparison with the standard barge platform, by considering still winds and regular waves with a zero direction and a wave height of $0.9 \mathrm{~m}$ and tanking into consideration the aforementioned environmental conditions.

\subsubsection{First Evaluated Period} of $6 \mathrm{~s}$.

Figure 7 shows the regular wave elevation with the amplitude of $0.9 \mathrm{~m}$ and period

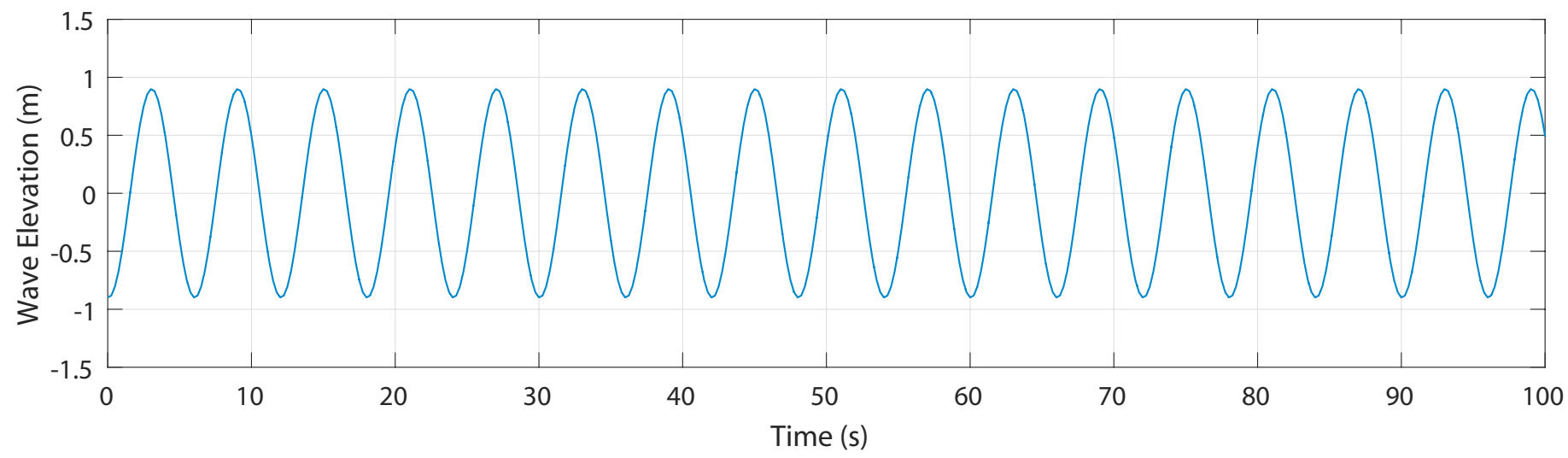

Figure 7. Wave elevation input.

From the RAOs for sway, roll and yaw illustrated in Figure 5b,d,f, we expect to see slight oscillations in the forenamed modes, as shown in Figure 8b,e,g. Also, as a result of those slight motions in lateral modes, side-to-side tower top moves slightly on the platforms, represented in Figure $8 \mathrm{~h}$.

At the period of $6 \mathrm{~s}$, Figure 5a illustrates that the Surge RAO (SRAO) for the standard barge is somewhat higher than that of the introduced platform. It is in a good agreement with the platform surge motions, shown in Figure 8a where the domain of oscillation for the standard barge is slightly higher than the platform with OWCs. 
Figure $5 \mathrm{c}$ indicates that the HRAO spectrum for the standard barge is slightly lower than that of the proposed platform at period $6 \mathrm{~s}$. It is demonstrated in Figure 8c that the standard barge oscillates less than the platform with OWCs.

According to the PRAO at period $6 \mathrm{~s}$ (Figure 6), the platforms have small oscillations in pitch. In addition, PRAO curves for the platforms are identical at that period which can be verified by Figure 8f. This Figure shows that slight pitch motions for both platforms are identical after transient response.

Finally, as a result of the slight platforms' pitch motion, fore-aft tower top follows the analogous behaviour, illustrated in Figure 8d.

(a)

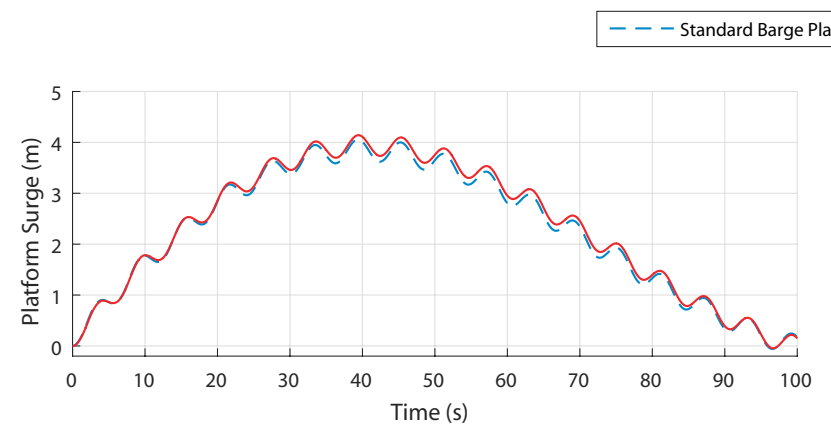

(b)

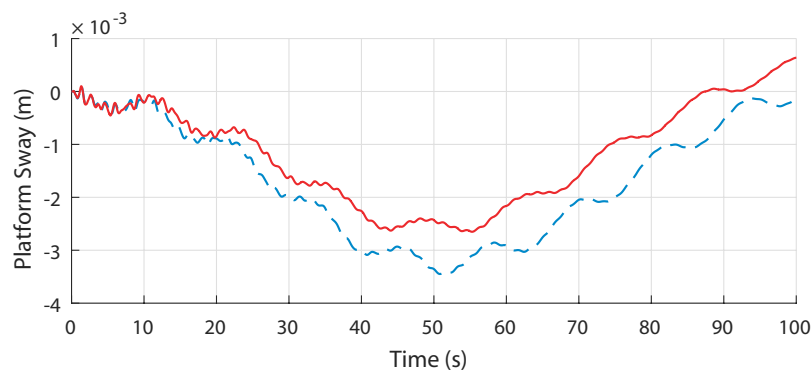

(c)

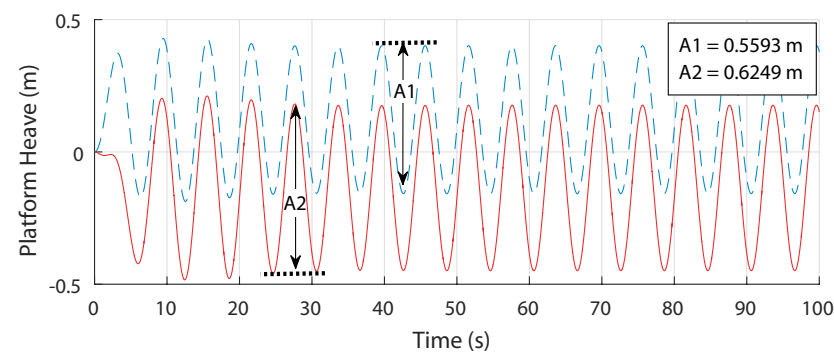

(d)

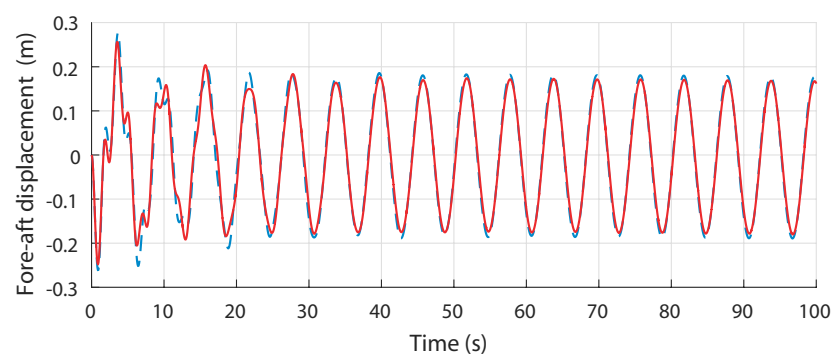

(e)

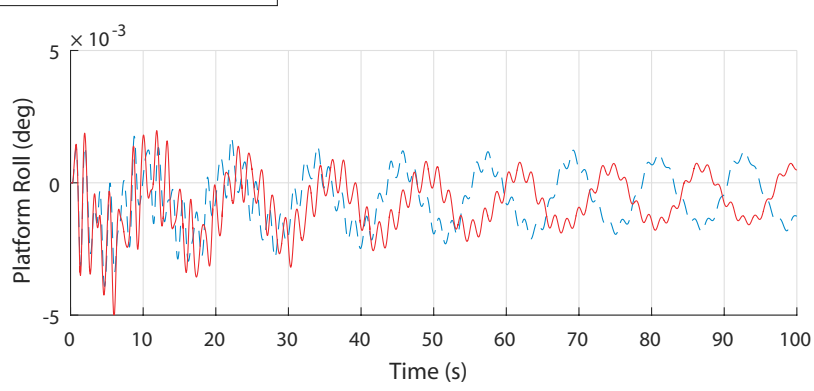

(f)

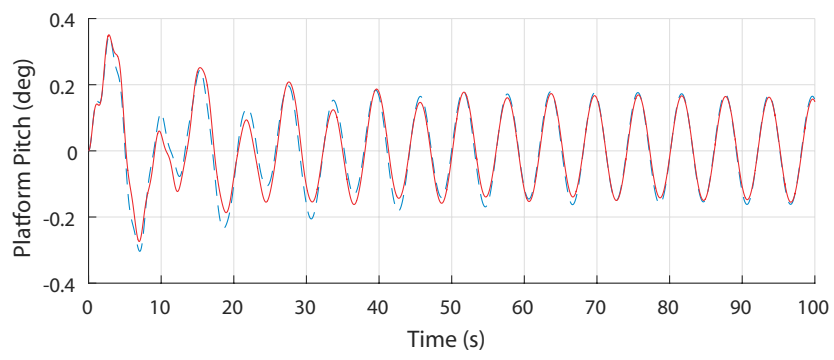

(g)
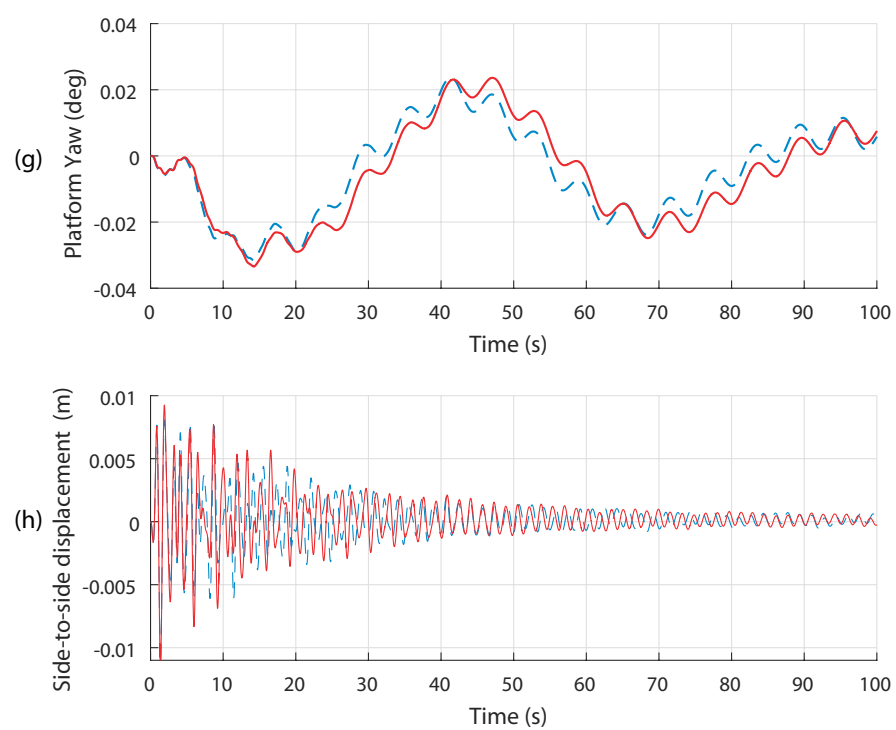

Figure 8. Platforms' modes for (a) Surge. (b) Sway. (c) Heave. (d) Fore-aft. (e) Roll. (f) Pitch. (g) Yaw. (h) Side-to-side.

\subsubsection{Second Evaluated Period}

The regular wave input with the period of $10 \mathrm{~s}$ and amplitude of $0.9 \mathrm{~m}$ can be seen in Figure 9 for the second region.

With consideration of the RAOs for sway, roll and yaw, shown in Figure $5 b, d, f$, it can be realized that no vibrations occur in those modes at period $10 \mathrm{~s}$. Also, side-to-side tower top mode does not excite because of no excitation in lateral modes. This can be confirmed in Figure 10b,e,g,h. 


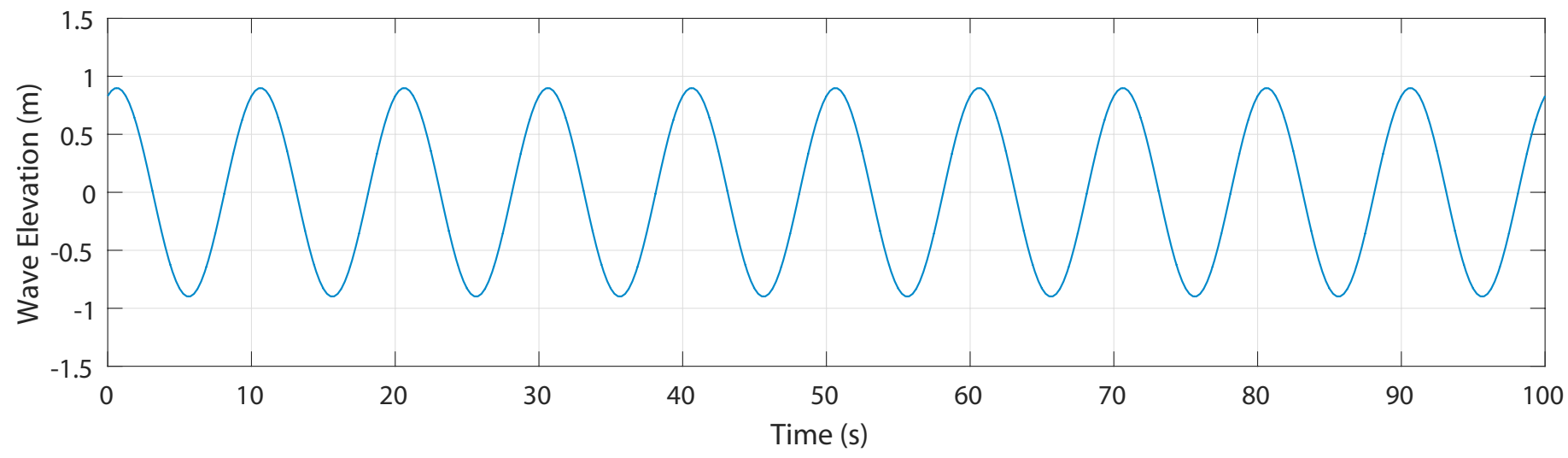

Figure 9. Wave elevation input.

(a)

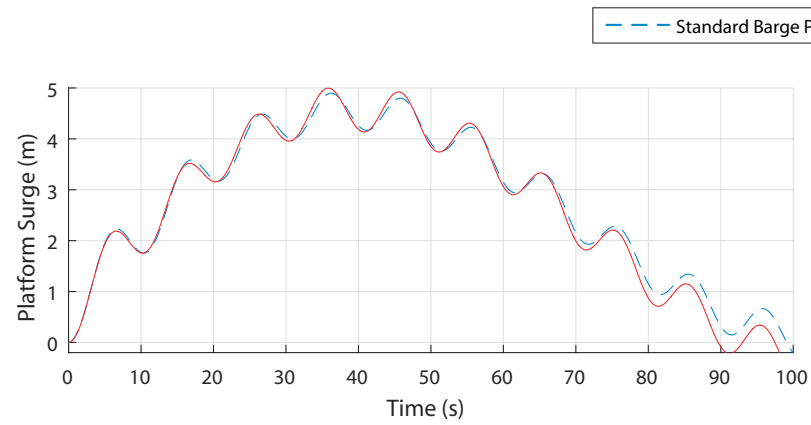

(b)

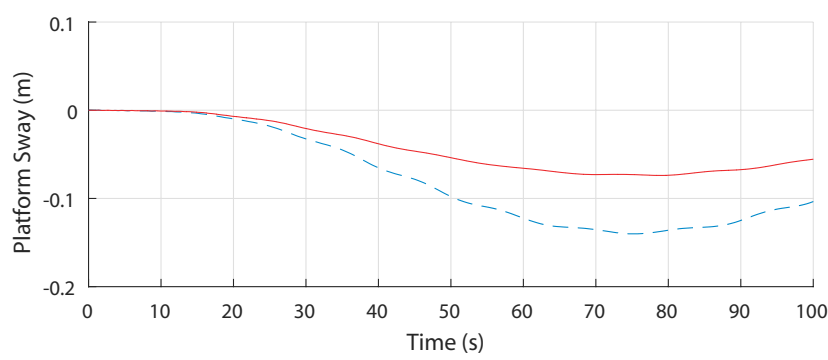

(c)

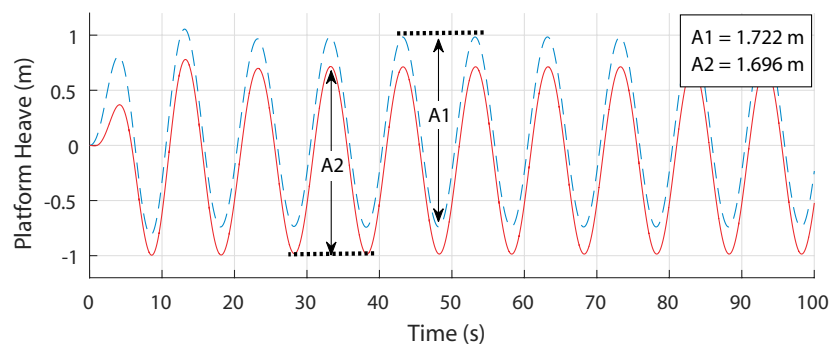

(d)

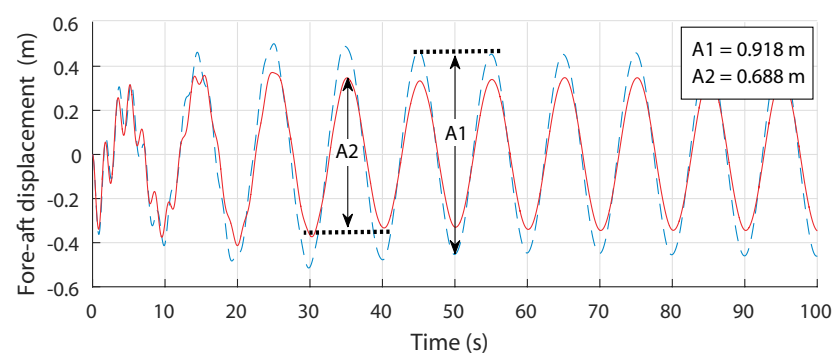

(e)

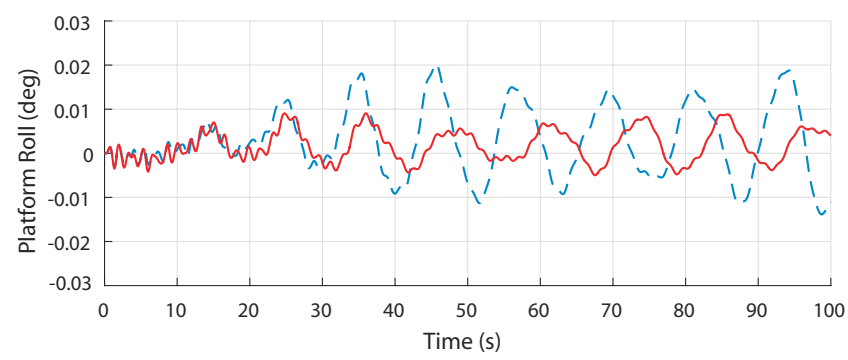

(f)

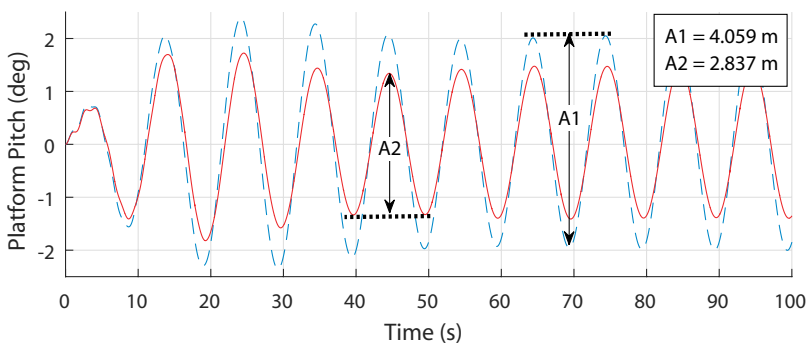

(g)
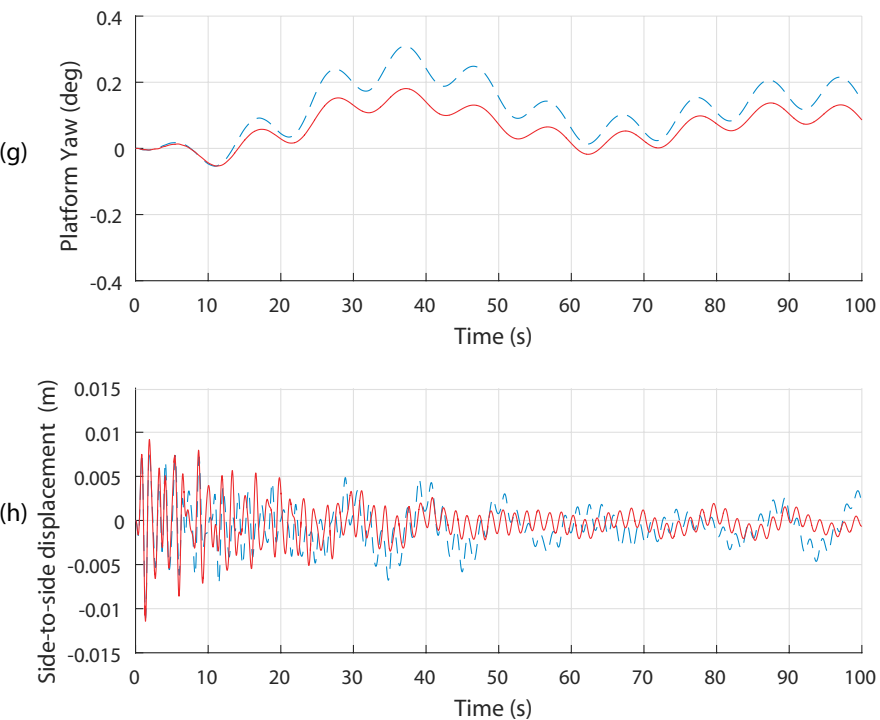

Figure 10. Platforms' modes for (a) Surge. (b) Sway. (c) Heave. (d) Fore-aft. (e) Roll. (f) Pitch. (g) Yaw. (h) Side-to-side.

The SRAO at the period of $10 \mathrm{~s}$ for the standard barge is lower than that of the proposed platform, illustrated in Figure 5a. It agrees with the platform surge motions, 
which after transient response, the domain of oscillation for the standard barge is lower than the second one, shown in Figure 10a.

Figure $5 \mathrm{c}$ indicates that the HRAO for the standard barge is higher than for the proposed platform with OWCs at period $10 \mathrm{~s}$. It is shown in Figure 10c that the proposed platform oscillates less than the standard barge. The domains of oscillation are $1.72 \mathrm{~m}$ and $1.69 \mathrm{~m}$ for the standard barge and proposed platform respectively.

The period of $10 \mathrm{~s}$ was chosen from green region, represented in Figure 6. We expect to see less pitch oscillation in the proposed platform than in the standard barge since the PRAO spectrum for the 4OWC-based barge is lower than the standard barge in the highlighted green zone. As it can be seen in Figure $10 \mathrm{f}$ after transient response, the proposed platform oscillates less than another one by 30.1 percent which shows the better performance and capability of the introduced platform in this period as well as the green zone.

Moreover, that pitch reduction has an impact on fore-aft tower top displacement. In this mode, the platform with OWCs oscillates less than the standard barge by 25.13 percent as illustrated in Figure 10d.

\subsubsection{Third Evaluated Period}

Figure 11 indicates a regular wave with the chosen period of $14 \mathrm{~s}$ and the amplitude of $0.9 \mathrm{~s}$ from the third region.

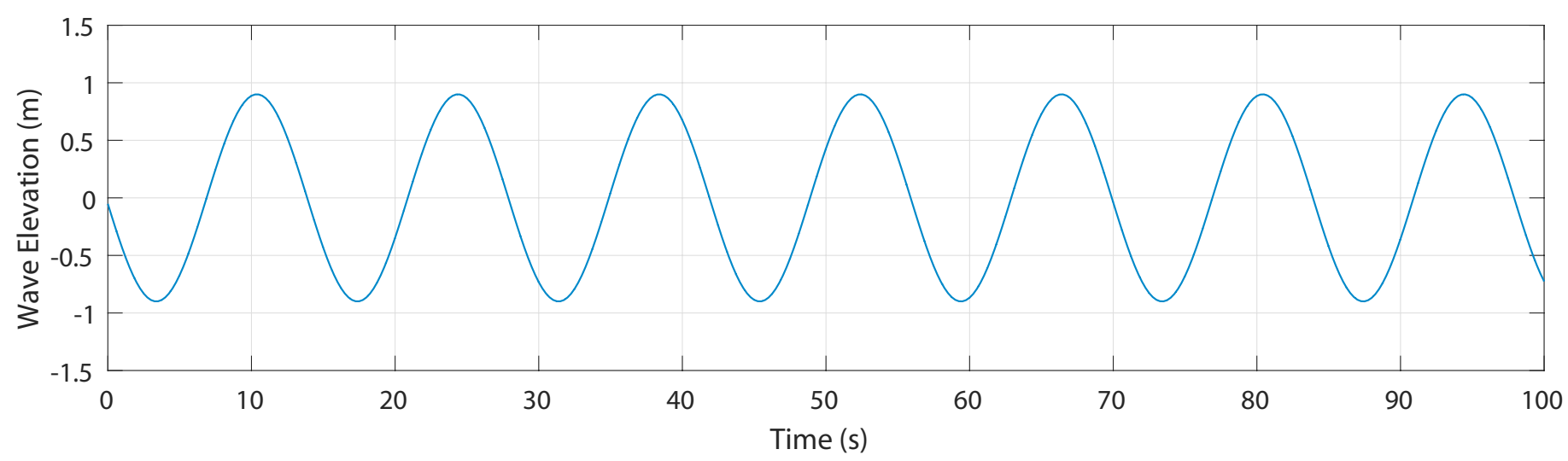

Figure 11. Wave elevation input.

Because of the wave direction, the lateral modes are not excited for different frequencies. This fact can be noticed in the RAOs shown in Figure 5b,d,f. At the period of $14 \mathrm{~s}$, the Platforms' sway, roll and yaw have quite minor oscillations illustrated in Figure 12b,e,g. As a result of those minor oscillations of the platforms, side-to-side tower top oscillates slightly, illustrated in Figure 12h.

It can be observed in Figure 5a that SRAO for the standard barge is slightly lower than the proposed platform. Hence, a slight lower oscillation in the standard barge compared to the second platform is expected. This lower vibration is shown in Figure 12a.

Through analysing the HRAO in Figure $5 c$, the HRAO for the standard barge is slightly lower than that of the proposed platform. It can be seen in Figure 12c that the proposed platform oscillates for $1.8 \mathrm{~m}$ and follows the wave input well while the standard barge oscillates for $1.78 \mathrm{~m}$, slightly less than $4 \mathrm{OWC}$-based platform.

PRAO at period $14 \mathrm{~s}$ from the third zone is considered and represented in Figure 6. We expect to see more pitch oscillation in the proposed platform than the standard barge since the PRAO spectrum for the 4OWC-based barge is higher than the standard barge in this zone. As it can be seen in Figure $12 \mathrm{f}$ after transient response, the proposed platform oscillates more than another one by 20 percent at period $14 \mathrm{~s}$ which shows that the standard barge has a better performance at this period as well as the third region. 
Additionally, the influence of those pitch angles is noticeable on fore-aft tower top displacement. In this mode, the platform with OWCs oscillates more than the standard barge by 27 percent as indicated in Figure 12d.

(a)
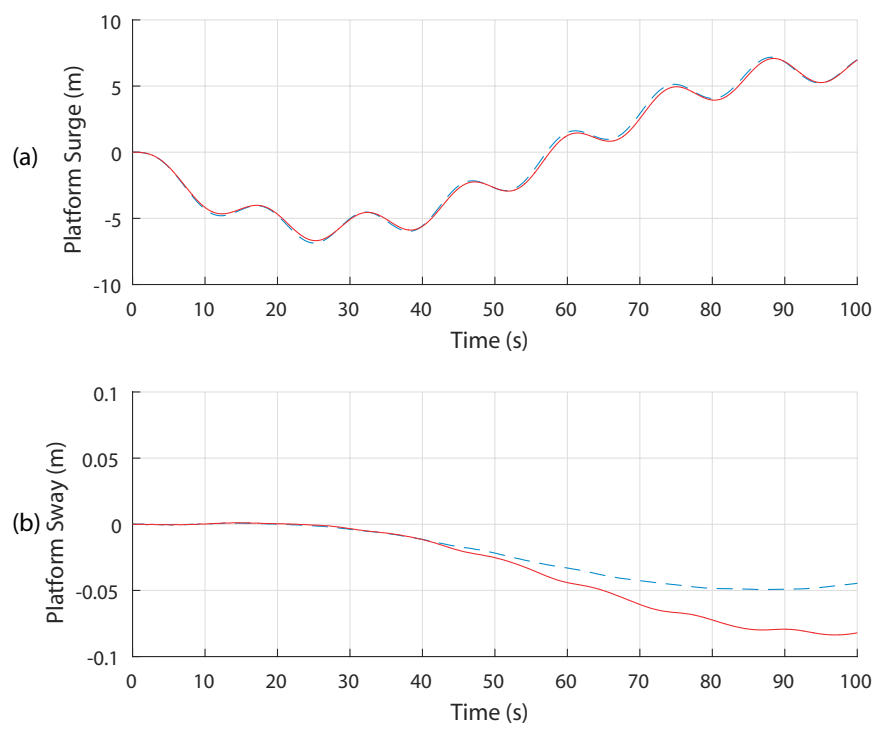

(c)

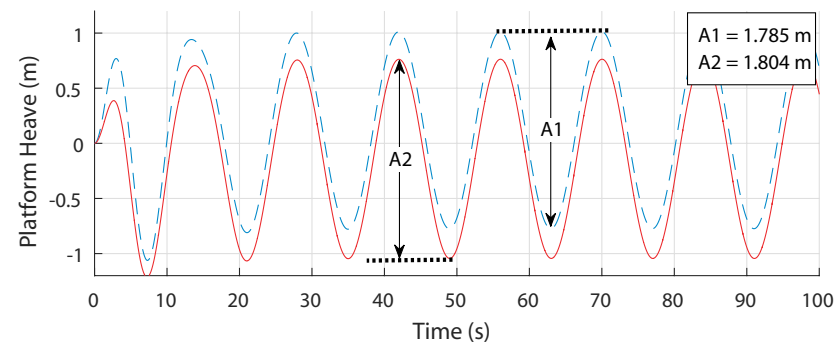

(d)

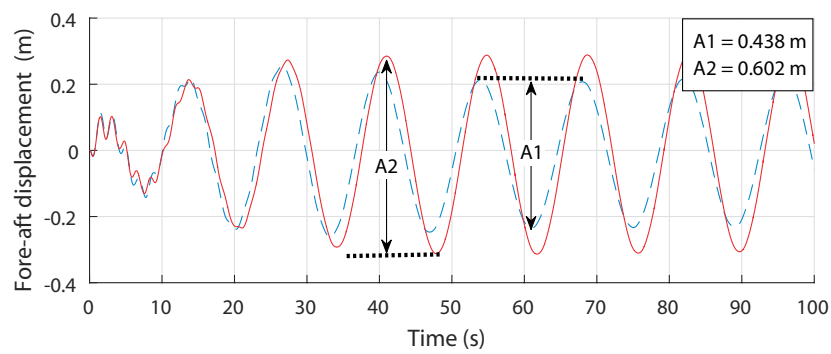

(e)

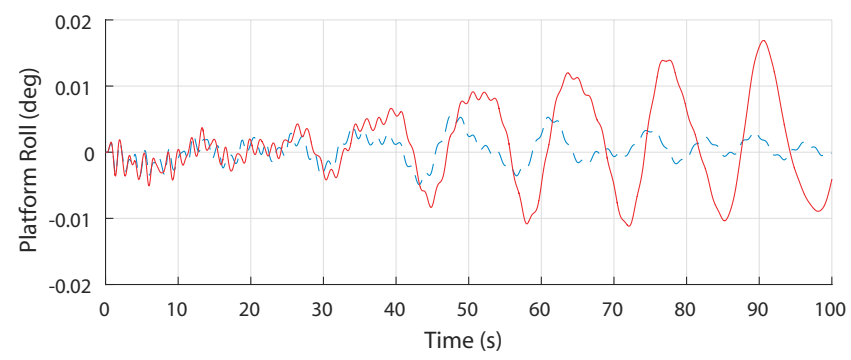

(f)

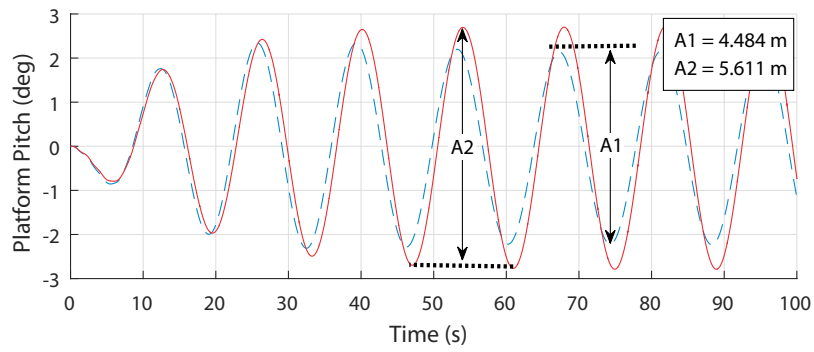

(g)
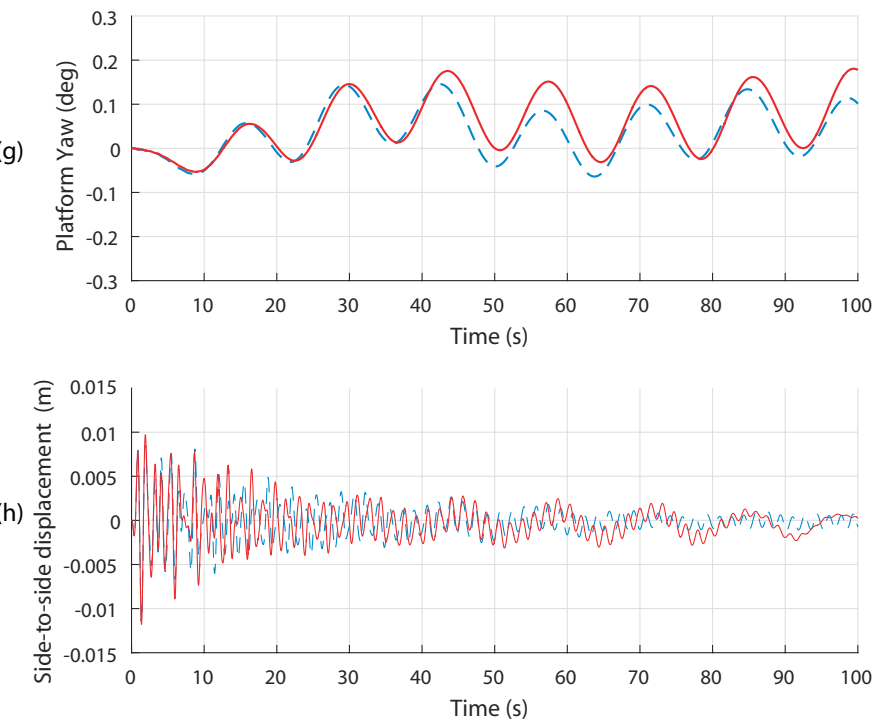

Figure 12. Platforms' modes for (a) Surge. (b) Sway. (c) Heave. (d) Fore-aft. (e) Roll. (f) Pitch. (g) Yaw. (h) Side-to-side.

\subsubsection{Fourth Evaluated Period}

The considered wave elevation input for this zone is with period $30 \mathrm{~s}$ and amplitude $0.9 \mathrm{~m}$ as shown in Figure 13.

The heading wave direction of zero degree causes the lateral modes of sway, roll, yaw and side-to side tower top are not excited at period $30 \mathrm{~s}$ as illustrated in Figure 14b,e,g,h. This is what we expected to happen from the modes RAOs in Figure 5b,d,f.

Since the SRAOs from Figure $5 \mathrm{a}$ at the period of $30 \mathrm{~s}$ are almost identical, the same oscillations in surge are expected for both platforms as shown in Figure 14a. This figure shows that both platforms oscillate in surge for $1.9 \mathrm{~m}$.

For the long-wave periods, HRAOs for both platforms are identical and unit, indicated in Figure $5 \mathrm{c}$. Therefore, It is predicted that both platforms have the same behavior in heave and follow the wave elevations as can be observed in Figure 14c. 
Figure 6 represents the PRAOs showing the minor values and identical curves for both platforms in long-wave periods. The expectation from the PRAOs is that both platforms have the same slight oscillations in pitch at period $30 \mathrm{~s}$, shown in Figure 14f. As it was stated, this region is like the first one in terms of pitch motion and both platforms have the same performance.

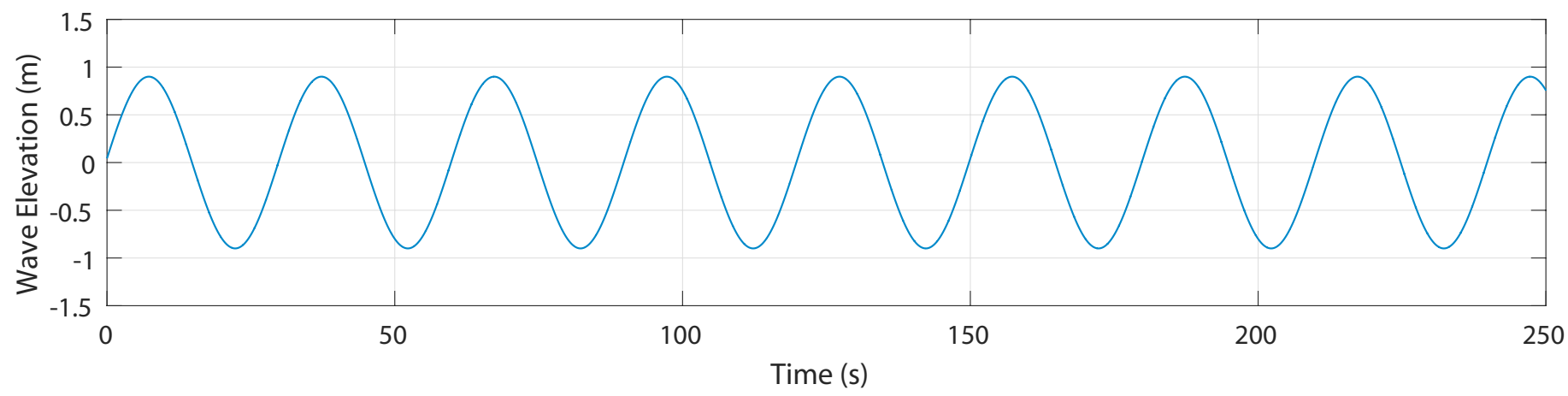

Figure 13. Wave elevation input.

(a)

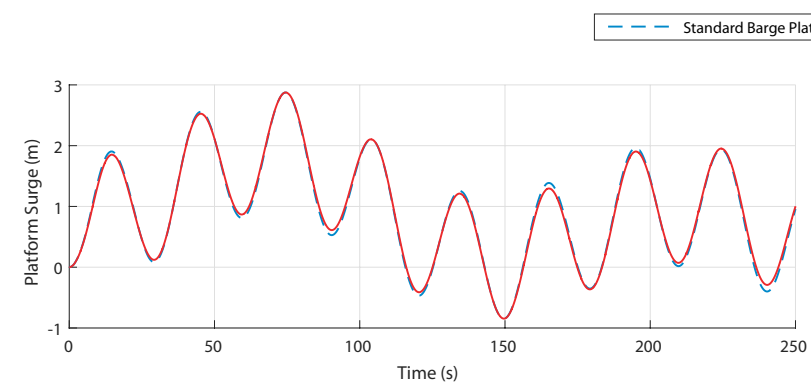

(b)

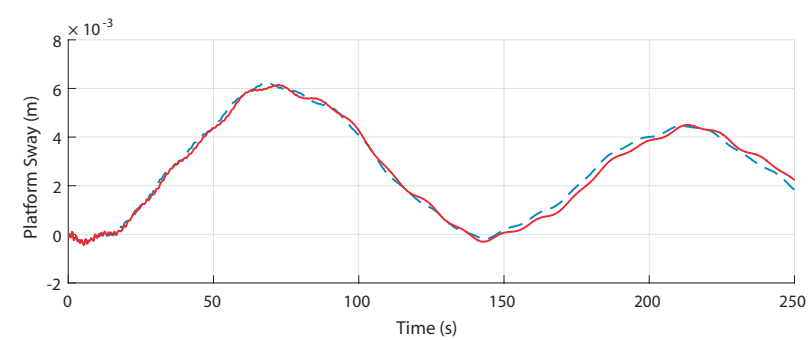

(c)

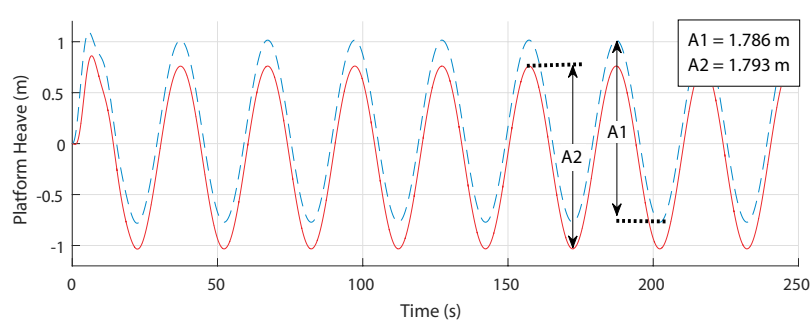

(d)

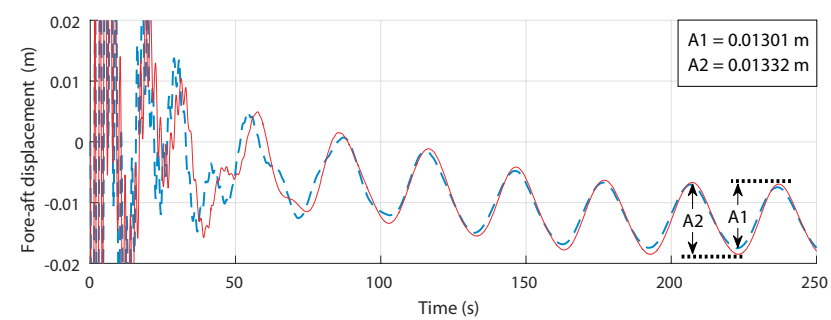

(e)

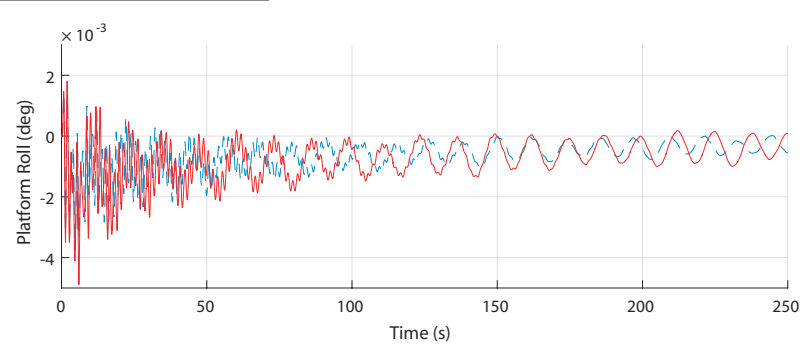

(f)

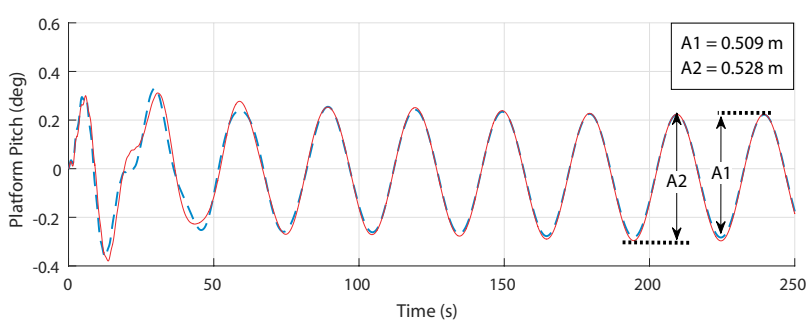

(g)

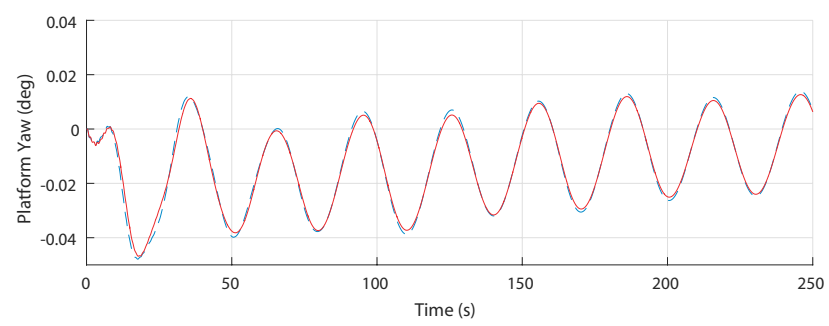

(h)

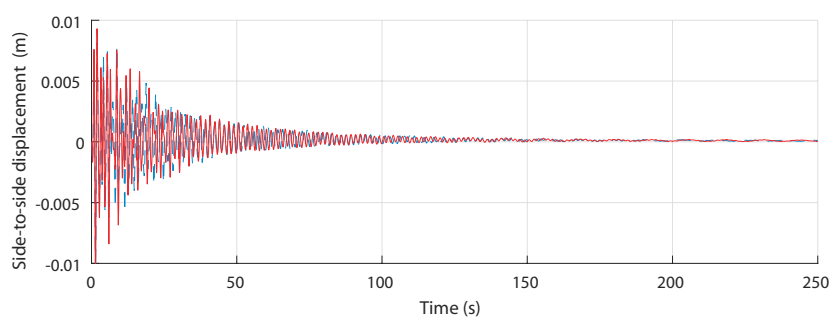

Figure 14. Platforms' modes for (a) Surge. (b) Sway. (c) Heave. (d) Fore-aft. (e) Roll. (f) Pitch. (g) Yaw. (h) Side-to-side. 
Besides, the influence of the pitch angles is notable on fore-aft tower top displacement, shown in Figure 14d. Fore-aft displacements for both platforms are about $13 \mathrm{~mm}$.

\section{Conclusions}

In this article, a novel design introduced for a barge platform. In this model, four OWCs were used in the standard barge platform to alleviate the platform oscillations especially in its rotational modes and tower top displacements. To evaluate the performance of our introduced platform, first the RAOs were depicted for different modes to show the behaviour of the system in frequencies. Then four specific periods were chosen for more evaluations.

The system's behaviour was analyzed for all the modes in periods. The reduction of pitch and fore-aft top tower displacements are the most important objectives in this study because they can lead to capture maximum wind supply.

The results showed that the proposed model for the pitch and fore-aft tower top modes could efficiently decrease the oscillations occurring in the platform by regular waves with periods $6.4 \mathrm{~s}-12.25 \mathrm{~s}$ (green zone). However, from the period of $12.25 \mathrm{~s}$ through $20 \mathrm{~s}$ (red zone), the standard barge platform had a better performance. For the rest of the periods (blue zone), differences between two platforms were not recognizable.

Four periods were evaluated in the last subsections. We showed that there are very small oscillations in sway, roll, yaw and side-to-side tower top displacements for both platforms in different periods. For the surge mode, the platforms oscillate the same in the periods of $6 \mathrm{~s}$ and $30 \mathrm{~s}$ while the standard barge moves slightly less than our proposed platform in periods $10 \mathrm{~s}$ and $14 \mathrm{~s}$. Analysis of the heave state for all the evaluated periods showed that the platforms oscillate almost similarly with very minor differences. Finally, the evaluations of the platforms indicated that both have the same behaviour in pitch and fore-aft tower top motions. It was clarified that for those modes, both platforms have the same oscillations in short-wave and long-wave periods whereas our proposed platform have a better performance in the period of $10 \mathrm{~s}$ and a worse performance in the period of $14 \mathrm{~s}$.

The present work and the performance analysis findings encourage the future implementation of a specific control strategy over the 4OWC-based barge platform. This will allow us to adequately govern the capture chamber air valve opening/closing for resonance frequencies within critical ranges so as to avoid undesired high oscillations that appear in traditional barge platforms.

Author Contributions: Conceptualization, P.A., F.M., I.G. and A.J.G.; Formal analysis, P.A., F.M., I.G. and A.J.G.; Investigation, P.A., F.M., I.G. and A.J.G.; Methodology, P.A., F.M., I.G. and A.J.G.; Supervision, F.M., I.G. and A.J.G.; Validation, P.A., F.M., I.G. and A.J.G.; Visualization, P.A., F.M., I.G. and A.J.G.; Writing-Original draft, P.A., F.M., I.G. and A.J.G.; Writing—Review \& editing, P.A., F.M., I.G. and A.J.G. All authors have read and agreed to the published version of the manuscript.

Funding: This work was supported in part by the Basque Government, through project IT1207-19 and by the MCIU/MINECO through the projects RTI2018-094902-B-C21 and RTI2018-094902-B-C22 (MCIU/AEI/FEDER, UE).

Institutional Review Board Statement: Not applicable.

Informed Consent Statement: Not applicable.

Data Availability Statement: Not applicable.

Conflicts of Interest: The authors declare no conflict of interest. 


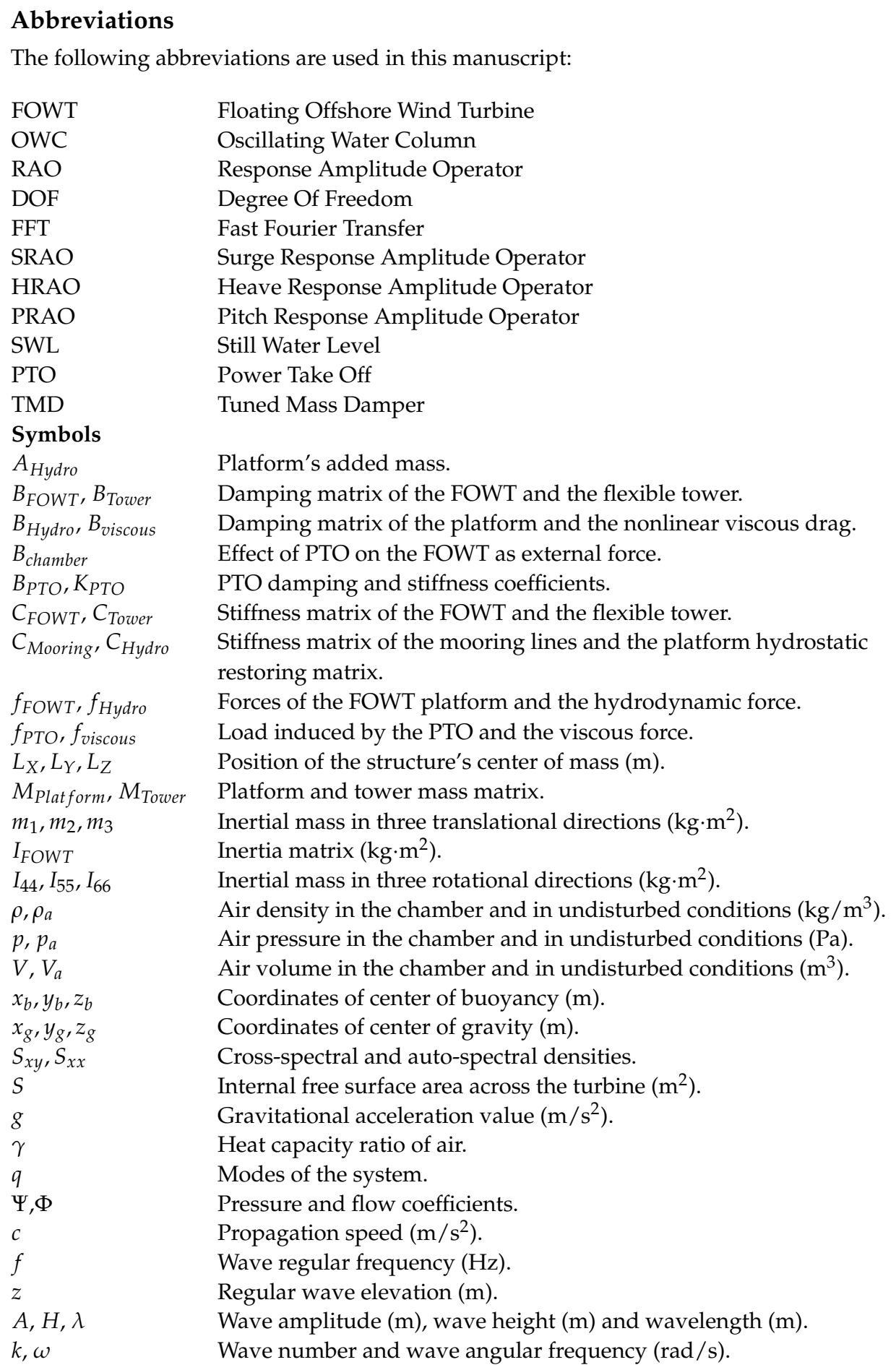

\section{References}

1. Junqueira, H.; Robaina, M.; Garrido, S.; Godina, R.; Matias, J.C. Viability of Creating an Offshore Wind Energy Cluster: A Case Study. Appl. Sci. 2021, 11, 308. [CrossRef]

2. Cottura, L.; Caradonna, R.; Ghigo, A.; Novo, R.; Bracco, G.; Mattiazzo, G. Dynamic modeling of an offshore floating wind turbine for application in the Mediterranean Sea. Energies 2021, 14, 248. [CrossRef]

3. Lemmer, F.; Yu, W.; Cheng, P.W. Iterative frequency-domain response of floating offshore wind turbines with parametric drag. J. Mar. Sci. Eng. 2018, 6, 118. [CrossRef]

4. López, M.; Rodríguez, N.; Iglesias, G. Combined Floating Offshore Wind and Solar PV. J. Mar. Sci. Eng. 2020, 8, 576. [CrossRef]

5. Liu, Y.; Xiao, Q.; Incecik, A.; Peyrard, C.; Wan, D. Establishing a fully coupled CFD analysis tool for floating offshore wind turbines. Renew. Energy 2017, 12, 280-301. [CrossRef] 
6. Yan, R.; Dunnett, S. Improving the Strategy of Maintaining Offshore Wind Turbines through Petri Net Modelling. Appl. Sci. 2021, 11, 574. [CrossRef]

7. Suzuki, H.; Sakai, Y.; Yoshimura, Y.; Houtani, H.; Carmo, L.H.; Yoshimoto, H.; Kamizawa, K.; Gonçalves, R.T. Non-Linear Motion Characteristics of a Shallow Draft Cylindrical Barge Type Floater for a FOWT in Waves. J. Mar. Sci. Eng. 2021, 9, 56. [CrossRef]

8. Si, Y.; Karimi, H.R. Gain scheduling $H 2 / H \infty$ structural control of a floating wind turbine. IFAC Proc. 2014, 47, 6788-6793. [CrossRef]

9. Benazzouz, A.; Mabchour, H.; El Had, K.; Zourarah, B.; Mordane, S. Offshore Wind Energy Resource in the Kingdom of Morocco: Assessment of the Seasonal Potential Variability Based on Satellite Data. J. Mar. Sci. Eng. 2021, 9, 31. [CrossRef]

10. Karimirad, M.; Koushan, K. WindWEC: Combining wind and wave energy inspired by hywind and wavestar. In Proceedings of the 2016 IEEE International Conference on Renewable Energy Research and Applications (ICRERA), Birmingham, UK, 20-23 November 2016; pp. 96-101.

11. Maria-Arenas, A.; Garrido, A.J.; Rusu, E.; Garrido, I. Control strategies applied to wave energy converters: State of the art. Energies 2019, 12, 3115. [CrossRef]

12. M'zoughi, F.; Garrido, I.; Garrido, A.J.; La Sen, D.; De La, M. ANN-Based Airflow Control for an Oscillating Water Column Using Surface Elevation Measurements. Sensors 2020, 20, 1352. [CrossRef] [PubMed]

13. Pérez-Collazo, C.; Greaves, D.; Iglesias, G. A review of combined wave and offshore wind energy. Renew. Sustain. Energy Rev. 2015, 42, 141-153. [CrossRef]

14. Chozas, J.F.; Kofoed, J.P.; Sørensen H.C. Predictability and Variability of Wave and Wind: Wave and Wind Forecasting and Diversified Energy Systems in the Danish North Sea; Aalborg University Department of Civil Engineering: Aalborg, Denmark, 2013.

15. Quevedo, E.; Delory, M.; Castro, A.; Llinas, O.; Hernandez, J. Modular multi-purpose offshore platforms, the TROPOS project approach. In Proceedings of the Fourth International Conference on Ocean Energy (ICOE), Dublin, Ireland, 17-19 October 2012; pp. 1-5.

16. Sharay, A.; Iglesias, G. The economics of wave energy: A review. Renew. Sustain. Energy Rev. 2015, 45, 397-408.

17. Tran, T.T.; Kim, D.H. The platform pitching motion of floating offshore wind turbine: A preliminary unsteady aerodynamic analysis. J. Wind. Eng. Ind. Aerodyn. 2015, 142, 65-81. [CrossRef]

18. Matha, D. Model Development and Loads Analysis of an Offshore Wind Turbine on a Tension Leg Platform with a Comparison to Other Floating Turbine Concepts (No. NREL/SR-500-45891); National Renewable Energy Lab. (NREL): Golden, CO, USA, 2009.

19. Kluger, J.M.; Slocum, A.H.; Sapsis T.P. A First-Order Dynamics and Cost Comparison of Wave Energy Converters Combined With Floating Wind Turbines. In Proceedings of the International Offshore and Polar Engineering Conference, San Francisco, CA, USA, 25-30 June 2017.

20. Haji, M.N.; Kluger, J.M.; Sapsis, T.P.; Slocum, A.H. A symbiotic approach to the design of offshore wind turbines with other energy harvesting systems. Ocean. Eng. 2018, 169, 673-681. [CrossRef]

21. Lackner, M.A. An investigation of variable power collective pitch control for load mitigation of floating offshore wind turbines. Wind Energy 2013, 16, 435-444. [CrossRef]

22. Zhang, Z.; Nielsen, S.R.; Blaabjerg, F.; Zhou, D. Dynamics and control of lateral tower vibrations in offshore wind turbines by means of active generator torque. Energies 2014, 7, 7746-7772. [CrossRef]

23. Yang, W.; Tian, W.; Hvalbye, O.; Peng, Z.; Wei, K.; Tian, X. Experimental research for stabilizing offshore floating wind turbines. Energies 2019, 12, 1947. [CrossRef]

24. Hu, Y.; Wang, J.; Chen, M.Z.; Li, Z.; Sun, Y. Load mitigation for a barge-type floating offshore wind turbine via inerter-based passive structural control. Eng. Struct. 2018, 177, 198-209. [CrossRef]

25. Zhang, Y.; Zhao, X.; Wei, X. Robust structural control of an underactuated floating wind turbine. Wind Energy 2020, 23, 2166-2185 [CrossRef]

26. Wei, X.; Zhao, X. Vibration suppression of a floating hydrostatic wind turbine model using bidirectional tuned liquid column mass damper. Wind Energy 2020, 23, 1887-1904. [CrossRef]

27. Ren, N.; Ma, Z.; Shan, B.; Ning, D.; Ou, J. Experimental and numerical study of dynamic responses of a new combined TLP type floating wind turbine and a wave energy converter under operational conditions. Renew. Energy 2020, 151, 966-974. [CrossRef]

28. Aubault, A.; Alves, M.; Sarmento, A.N.; Roddier, D.; Peiffer, A. Modeling of an oscillating water column on the floating foundation WindFloat. In Proceedings of the International Conference on Offshore Mechanics and Arctic Engineering, Rotterdam, The Netherlands, 19-24 June 2011; pp. 235-246.

29. Hu, J.; Zhou, B.; Vogel, C.; Liu, P.; Willden, R.; Sun, K.; Zang, J.; Geng, J.; Jin, P.; Cui, L.; et al. Optimal design and performance analysis of a hybrid system combing a floating wind platform and wave energy converters. Appl. Energy 2020, $269,114998$. [CrossRef]

30. Sarmiento, J.; Iturrioz, A.; Ayllón, V.; Guanche, R.; Losada, I.J. Experimental modelling of a multi-use floating platform for wave and wind energy harvesting. Ocean. Eng. 2019, 173, 761-773. [CrossRef]

31. Yu, J.; Li, Z.; Yu, Y.; Hao, S.; Fu, Y.; Cui, Y.; Xu, L.; Wu, H. Design and Performance Assessment of Multi-Use Offshore Tension Leg Platform Equipped with an Embedded Wave Energy Converter System. Energies 2020, 13, 3991. [CrossRef]

32. Slocum, A.; Kluger, J.; Mannai, S. Energy Harvesting and Storage System Stabilized Offshore Wind Turbines. In Proceedings of the 2019 Offshore Energy and Storage Summit (OSES), Brest, France, 10-12 July 2019; pp. 1-6. 
33. Kamarlouei, M.; Gaspar, J.F.; Calvario, M.; Hallak, T.S.; Mendes, M.J.; Thiebaut, F.; Soares, C.G. Experimental analysis of wave energy converters concentrically attached on a floating offshore platform. Renew. Energy 2020, 152, 1171-1185. [CrossRef]

34. Jonkman, J.M. Dynamics Modeling and Loads Analysis of an Offshore Floating Wind Turbine (No. NREL/TP-500-41958); National Renewable Energy Lab. (NREL): Golden, CO, USA, 2007.

35. M'zoughi, F.; Garrido, I.; Garrido, A.J.; De La Sen, M. Self-adaptive global-best harmony search algorithm-based airflow control of a wells-turbine-based oscillating-water column. Appl. Sci. 2020, 10, 4628. [CrossRef]

36. M'zoughi, F.; Garrido, I.; Bouallègue, S.; Ayadi, M.;Garrido, A.J. Intelligent Airflow Controls for a Stalling-Free Operation of an Oscillating Water Column-Based Wave Power Generation Plant. Electronics 2019, 8, 70. [CrossRef]

37. M'zoughi, F.; Bouallegue, S.; Garrido, A.J.; Garrido, I.; Ayadi, M. Fuzzy gain scheduled PI-based airflow control of an oscillating water column in wave power generation plants. IEEE J. Ocean. Eng. 2018, 44, 1058-1076. [CrossRef]

38. Jonkman, J.; Butterfield, S.; Musial, W; Scott, G. Definition of a 5-MW Reference Wind Turbine for Offshore System Development (No. NREL/TP-500-38060); National Renewable Energy Lab. (NREL): Golden, CO, USA, 2009.

39. Ramachandran, G.K.V.; Robertson, A.; Jonkman, J.M.; Masciola, M.D. Investigation of Response Amplitude Operators for Floating Offshore Wind Turbines (No. NREL/CP-5000-58098); National Renewable Energy Lab. (NREL): Golden, CO, USA, 2013.

40. Pintelon, R; Schoukens, J. System Identification: A Frequency Domain Approach; John Wiley \& Sons: Hoboken, NJ, USA, 2012; pp. 54-64. 